Western University

Scholarship@Western

Department of Economics Research Reports

Economics Working Papers Archive

1980

\title{
The Family, Inheritance and the Intergenerational Transmission of Inequality
}

Nigel Tomes

Follow this and additional works at: https://ir.lib.uwo.ca/economicsresrpt

Part of the Economics Commons

Citation of this paper:

Tomes, Nigel. "The Family, Inheritance and the Intergenerational Transmission of Inequality." Department of Economics Research Reports, 8001. London, ON: Department of Economics, University of Western Ontario (1980). 
ISBN: $\quad 0-7714-0153-1$

RESEARCH REPORT 8001

THE FAMILY, INHERITANCE AND THE INTERGENERATIONAL TRANSMISSION

OF INEQUALITY

by

Nige1 Tomes

January, 1980 


\title{
THE FAMILY, INHERITANCE AND THE INTERGENERATIONAL TRANSMISSION OF INEQUALITY
}

\author{
Nigel Tomes \\ Department of Economics \\ The University of Western Ontario \\ London, Ontario N6A 5C2 \\ Canada
}

December 1979

\begin{abstract}
An earlier version of this paper, under the title "Inheritance and the Intergenerational Transmission of Inequality: Theory and Empirical Results," was presented in workshops at the University of Chicago, Queen's University and U.W.O. Workshop participants provided helpful comments. Dorothy Worth provided programming assistance. I would like to thank Marvin B. Sussman and Judith N. Cates for permission to use their data. Responsibility for any errors is my own.
\end{abstract}




\section{Abstract}

Unequal inheritance of material wealth is cammonly considered to be a major cause of inequality in consumption. A model of the intergenerational transmission of inequality is presented in which parents transfer resources to their children either as human capital or bequests of material wealth. Since inheritance is a means of redistributing income between members of the family, unequal inheritance may either increase or reduce consumption inequality. Differences in inherited wealth resulting from unequal parental incomes increase the inequality in recipient's consumption. However unequal bequests due to differences between families in the endowed ability of children and the costs of producing human capital are shown to be equalizing. Empirical results confirm these predictions: The inheritance of children is inversely related to both children's income and parental education. Thus inheritance is "compensatory" in that (ceteris paribus) low incane children receive more than their advantaged contempories. 
"The ultimate difficulties...center around the problem of social continuity in a world where individuals are born naked, destitute, helpless, ignorant and untrained,... . The fundamental fact about society.... is that it is made up of individuals who are born and die and give place to others; and...that it is dependent upon the utilization of three great accumulating funds of inheritance from the past, material goods and appliances, knowledge and skill, and morale [which]... must in some manner be carried forward to new individuals devoid of all these things as older individuals pass out ... - [T]he institutions of the private family and private property, inheritance and bequest and parental responsibility, afford one way for securing more or less tolerable results in grappling with this problem."

Frank H. Knight (1921, reprinted 1957) pp. 374-5. 
THE FAMILY, INHER ITANCE AND THE INTERGENERATIONAL

TRANSMISSION OF INEQUALITY

\section{INTRODUCTION}

Inequality in economic status and the extent to which inequality is reproduced in succeeding generations--the degree of "social mobility"--continue to be objects of social concern and the subject of investigation by social scientists. It has long been suspected that the institution of the family plays a major role in the generation and transmission of inequality and may severely limit the ability of public policy to alter the existing social order (Knight 1921, pp. 374-5).

The role of the family has been examined in a large number of empirical studies. A decade of research on the ability-schooling-income nexus has quantified the effects of "family background" on measures of achievement (occupation or income) both directly and via intermediate variables such as schooling. ${ }^{1}$ These results may be interpreted within the human capital framework (Becker 1967, Parsons 1975). In addition to the large and growing human capital literature, there exists a research tradition which has examined the role of inherited material wealth in producing and perpetuating inequality (Stamp 1926, Wedgwood 1929, Harbury and associates 1963, 1973, 1976, Blinder 1973, 1976b and Menchik 1979).

Research on the intergenerational transmission of inequality has, for the most part, been conducted within the context of these two mutually exclusive approaches. However, models of intergenerational transfer behavior recently proposed by Becker (1974), Ishikawa (1975) and Blinder (1976a), strongly suggest the possibility of substitution between these alternative modes of transfer and the dependence of both types of transfer on a common set of ability and opportunity variables. Thus, the 'ability' of children and the 
education of parents--important determinants of children's schooling should also influence parent-child transfers of material wealth. In these models parentchild transfers are motivated by altruism, in that either the child's income (Becker) or the total (financial and human capital) bequest (Blinder, Ishikawa) enters the parent's utility function. The optimum form of transfers is determined by cost minimization with human capital--the initial least-cost mode of transfer, being subsequently dominated by transfers in the form of material wealth.

The observation that $55-60 \%$ of individuals do not receive an inheritance of material wealth (Blinder 1973, Blomqvist 1979) suggests that there are two categories of households: those making transfers exclusively in the form of human capital and who are at a corner solution making no transfers in the form of material wealth, and secondly households making transfers in both forms. These two groups (regimes) are predicted to respond differently to variations in opportunities that result from differences in parental income and education (Edwards and Grossman 1977).

Recent models of family transfer behavior suggest that the family may not contribute as much to inequality as is commonly thought. Since parents are predicted to adjust the magnitude of intergenerational transfers in response to differences in the endowments of children, the institution of the family permits a redistribution of resources that tends to equalize consumption, both between parents and children (Stiglitz 1978, Becker-Tomes 1979) ${ }^{2}$ and between disadvantaged and advantaged siblings (Becker-Tomes 1976, Griliches 1979). Due to the role of the family in equalizing consumption, government redistribution measures may have little, zero or even a perverse effect on the distribution of income and consumption (Barro 1974, Becker-Tomes 1979). 
The purpose of this paper is to present and empirically test an altruistic model of the intergenerational transmission of inequality within the family. In this model, bequests of material wealth and human capital investment represent substitute forms of intergenerational transfer and are simultaneously determined. The present paper extends previous work in a number of directions. First, previous studies of inheritance (Adams 1980, Menchik 1979) have been concerned with estimating the income elasticity of bequests--and hence the extent to which unequal parental incomes are responsible for inequality in subsequent generations. ${ }^{3}$ In contrast this paper emphasizes the response of parental bequests to differences in children's incomes, which result from differences in child ability or differences in the efficiency with which parents are able to produce human capital in their children. Since intergenerational transfers serve in part to redistribute resources between the generations, holding parental income constant, the inheritance a child receives is predicted to be inversely related to his income. Thus, within parental income strata, bequests of material wealth are predicted to be equalizing. Further, if parents with greater education are more efficient at producing learning or earning skills in their children, the progeny of more educated parents will receive higher lifetime incomes from human capital. As a result, the equalizing role of the family will also be reflected in an inverse relationship between inherited wealth and parental education.

Second, the choice of family size, a variable emphasized in simulation models (Pryor 1973), and empirical studies (Lebergott 1976, Blomqvist 1979), is treated as endogenous, 4 as suggested by the "new microeconomic" approach to fertility. Since a large family size increases the cost of achieving a given per capita bequest for each child and conversely a larger desired bequest per child raises the cost of having an additional child, 
we predict an inverse relationsh ip between material wealth transfers and family size. Third, in addition to extending the "two-regime" model to the context in which family size is endogenous, this paper reports direct empirical tests of the extended model. In the absence of data on material wealth transfers, previous investigators (Edwards and Grossman 1977, Leibowitz and Friedman 1979) were restricted to indirect tests of that model.

Empirical tests of the model are performed using a uniquely rich data set which contains information on the inheritance, income and schooling of children and the occupation, education and family size of parents.

The major empirical results offer strong support for the altruistic model of family intergenerational transfers. There are two important results here:

First, holding parental income constant, the inheritance received by children is inversely related to the child's income. This result supports the prediction that within parental income strata, inheritance is equalizing-low income children are "compensated" in that they receive larger bequests of material wealth and conversely high income children are "taxed" by parents in that they receive smaller bequests. Thus there is evidence that family intergenerational transfers in the form of inherited material vealth perform the role of equalizaing the distribution of resources, between successive generation of the family.

Second, the empirical results support the view that substitution between human capital investment and bequests occurs because parents differ in their ability to produce human capital in their children. Other things equal, more educated parents are more efficient at producing income-earning skills in their children--as measured both by child schooling and income. As a consequence the children of more educated parents receive lower transfers 
in the form of material wealth.

These data also offer some support of the view that there exist two distinct categories of households, for whom the determinants of human capital investment differ. Consistent with the two-regime model, the schooling of children who receive a positive inheritance is found to be unrelated to parental income and positively related to parental education. Conversely for children receiving a bequest of zero, the income elasticity of schooling is positive and children's schooling is unrelated to parental education. Lastly, there is evidence of a strong inverse relationship between family size and per capita parent-child transfers, as suggested by "quality-quantity" models of choice.

The plan of the remainder of the paper is as follows: Section 2 outlines a model of the simultaneous determination of inheritance, human capital investment and family size, within the context of a family in which parents have an altruistic concern for the well-being of their immediate descendents. The comparative static properties are examined and predictions are derived. In Section 3 the data are described and the model is specified empirically. Empirical results are reported in Section 4. Finally, Section 5 presents a summary and conclusions.

\section{A MODEL OF INHERITANCE, HUMAN CAPITAL INVESTMENT AND FAMILY SIZE}

Let us abstract from uncertainty and lifecycle factors and consider a static, certain world in which individuals, endowed with perfect foresight live for two periods--initially as a "child" and subsequently as a "parent". Generations of the family are assumed to be interdependent and overlapping. Parental fertility and the transmission of resources to children are assumed to be motivated by altruism, in that the number of 
children and their per capita consumption enter the parent's utility function, together with the parent's own consumption. This utility function may be written as:

$$
U=U\left(n, z_{c}, z_{p}\right)
$$

where $\mathfrak{n}$ is the number of children and $z_{c}$ is the per capita consumption of children during their subsequent tenure as parents. For simplicity per capita consumption is assumed to be the same for all $\mathrm{n}$ children within a given family. $z_{p}$ represents the aggregate consumption of parents. 6

Individuals are assumed to enter the world with an endowment of income, that is determined by such factors as genetic or cultural inheritance, government fiscal and social policy, exogenous economic growth and random "luck". For simplicity, I shall assume that all children within a given family possess equal endowments. Thus endowed income may vary across families, but not within families. 7

Motivated by their altruism, parents may augment the consumption of their children either by investing in their human capital or via direct transfers of material wealth. ${ }^{8}$ The relationship between the child's consumption and parent-child transfers is determined by the incomeexpenditure constraint of the next generation and the technology described by the income-generating function:

$$
z_{c}=I_{c}=e+\beta h(x, e) x+a=e+k+a
$$

where $k=\beta h(x, e) x$ and $h_{x}<0, h_{e} \geq 0$

The left-hand side of (2) represents the child's income-expenditure constraint, which indicates that in the absence of transfers by the child to the third and subsequent generations, consumption equals income. 9 The right-hand side of (2) defines income in terms of its proximate determinants: e represents the endowed income of the child, $k$ the income from human capital, 
and a represents the child's income from material wealth. ${ }^{10}$ Financial asset markets are assumed perfect, so that the rate of return on material wealth is constant and independent of the individual's stocks of human and non-human capital.

In general both market purchased goods (e.g., tuition) and homeproduced inputs (e.g., the time of parents) enter the production function for human capital. For simplicity we make the assumption that market purchased goods and home produced inputs are perfect substitutes. ${ }^{11}$ Under these circumstances the single aggregate input $(x)$, enters the production function. While the market return on human capital is assumed constant, due to the limited length of life and the finiteness of individual capacities (represented by e), investment in the human capital of a given individual is subject to diminishing returns. In the above formulation this is incorporated by assuming that the average (and margina1) product of the aggregate input (x) into children's human capital is diminishing (i.e., $h_{x}<0$ ).

The return to (home and market) inputs in the production of children's earning skills is also permitted to depend upon the child's characteristics--in the form of the child's endowments. To the extent that the child's endowment represents the "ability" to learn, greater child endowments will be associated with greater income for given inputs (i.e., $h_{e}>0$ ).

The parameter $\beta$ represents the level of parental efficiency and is assumed to operate in a manner equivalent to technological progress, increasing the next generation's income for given inputs and child endowments. Parental human capital is therefore. assumed not only to yield a market return in the form of increased parental income, but also a non-market return in the form of the ability to generate income for their children (Leibowitz, 1974). Holding parental income (and therefore market efficiency) constant, a larger value of the - 
parameter $\beta$ represents a greater level of non-market efficiency. In the subsequent analysis parental income and efficiency are emphasized as causal factors in the intergenerational transmission of inequality.

In the absence of intra-family public goods and fixed cost components, and given identical children, parental expenditures on the next generation are simply the product of per capita transfers and the number of children, valued at the appropriate prices. ${ }^{12}$ The Full Income constraint of parents can therefore be written as:

$$
I_{p}=z_{p}+p n x+p_{a}^{n a}
$$

where parental consumption $\left(z_{p}\right)$ is the numeraire, $I_{p}$ is the full income of parents, $\mathrm{p}$ is the unit price of human capital inputs, and $\mathrm{p}_{\mathrm{a}}$ is the cost of increasing the asset income of each child by $\$ 1 .{ }^{13}$ pnx and $p_{a}{ }^{n a}$ represent (respectively) the total expenditures by parents on the human capital and material wealth of the next generation. In these two components of expenditure, per capita transfers ("quality") and the number of children ("quantity") enter multiplicatively--a property that produces some novel implications concerning the interdependence of family size and intergenerational transfers.

THE COMMODITY DEMAND FUNCTIONS

The allocation problem of parents is to maximize utility (1) subject to (2) and (3). The first order conditions for an interior solution are:

$$
\begin{aligned}
& \frac{U_{\mathrm{p}}}{\Psi}=1 \equiv \pi_{\mathrm{p}} \\
& \frac{\mathrm{U}_{\mathrm{c}}}{\Psi}=\frac{\mathrm{pn}}{\beta \mathrm{h}(\cdot)(1-\eta)}=\mathrm{p}_{\mathrm{a}} \mathrm{n} \equiv \pi_{\mathrm{c}} \\
& \frac{\mathrm{U}_{\mathrm{n}}}{\Psi}=\mathrm{px}+\mathrm{p}_{\mathrm{a}} \mathrm{a}=\frac{\mathrm{pk}}{\operatorname{\beta h}(\cdot)}+\mathrm{p}_{\mathrm{a}} \mathrm{a} \equiv \pi_{\mathrm{n}}
\end{aligned}
$$


where $h(\cdot)=h(x, e), \eta=-h_{x} x / h(\cdot), 0<\eta<1$, $\Psi$ is the marginal utility of parental income, $U_{i}$ is the marginal utility of consumption by the $i^{\text {th }}$ generation and $U_{n}$ is the marginal utility of family size.

The marginal rate of substitution between each commodity and parental income is equated to the marginal cost defined by the first order conditions $\left(\pi_{j}\right.$ for the $j^{\text {th }}$ commodity). The interaction of "quality and quantity" dimensions of choice is reflected in the fact that the marginal costs of heir's consumption and family size $\left(\pi_{c}\right.$ and $\pi_{n}$ respectively) depend not only on prices, but also on the level of commodity outputs. The marginal cost of children's per capita consumption is positively related to the number of children, and the marginal cost of numbers depends on both human capital investment and material wealth transfers. Because of this interdependence we predict an inverse relationship between family size and parent-child transfers. The first-order conditions also imply that, in order to directly estimate the underlying income and substitution parameters, measures of both human capital and asset transfers should enter the demand function for the number of children, and family size may be an important determinant of children's per capita consumption and intergenerational transfers.

The optimum scale and mode of intergenerational transfers are determined by the first order conditions (4) and (5). The solution is shown graphically in Figure 1a, where the vertical axis represents the per capita consumption of children and the horizontal axis the parent's consumption. ${ }^{14}$ The points $\varepsilon_{1}, \varepsilon_{2}, \varepsilon_{3}$ represent the endowment points when each child has an endowed income of $e$ and parental income takes on values $I_{p}^{1}, I_{p}^{2}, I_{p}^{3}$ (respectively). The loci $k_{i} \varepsilon_{i}$ represent the opportunities for intergenerational transfer via human capital investment for each level of parental income, while the lines tangent to $b_{1}, b_{2}, b_{3}$ represent opportunities via the transfer of material wealth at these respective income levels. On the assumption that the marginal 


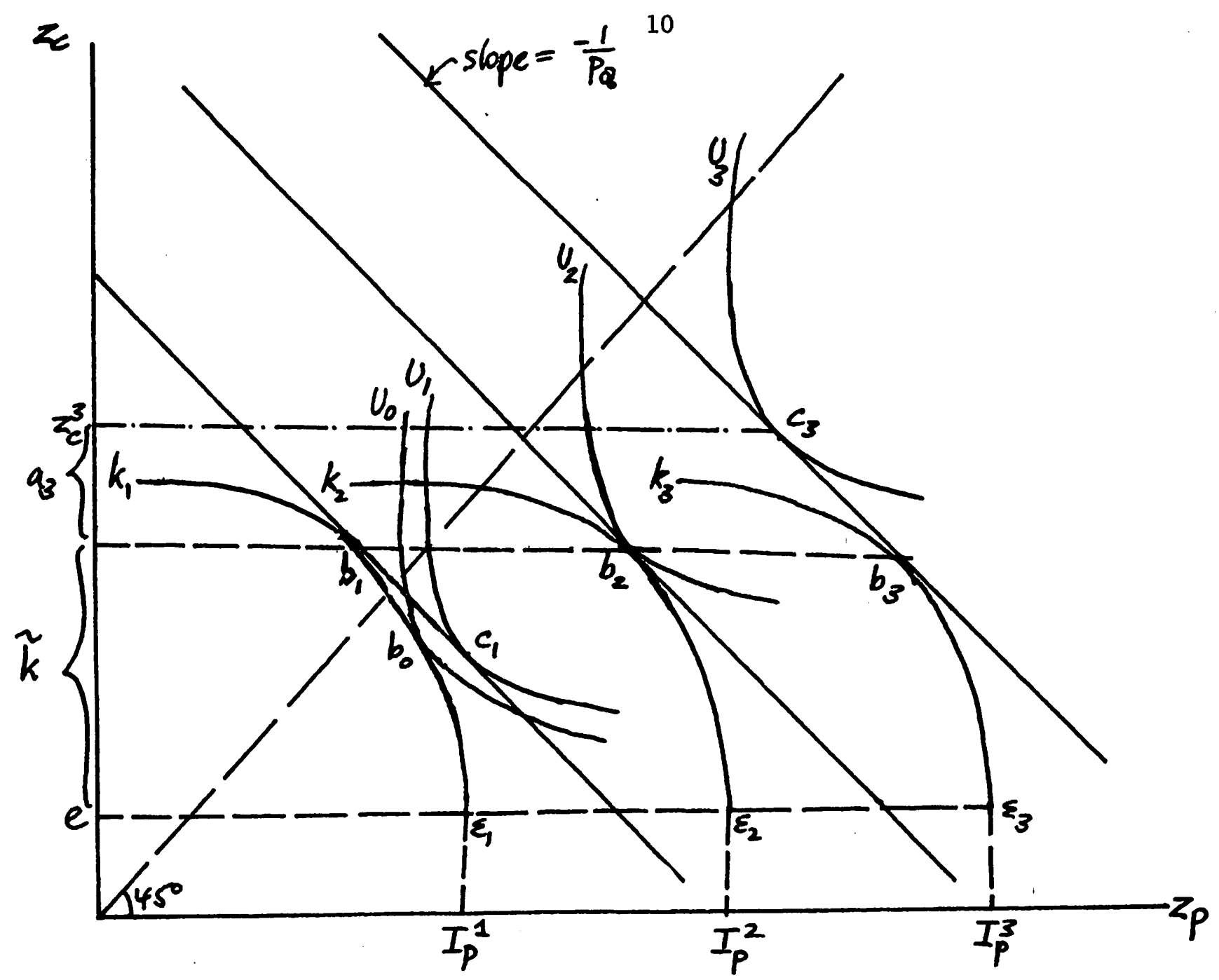

Figure 1a.

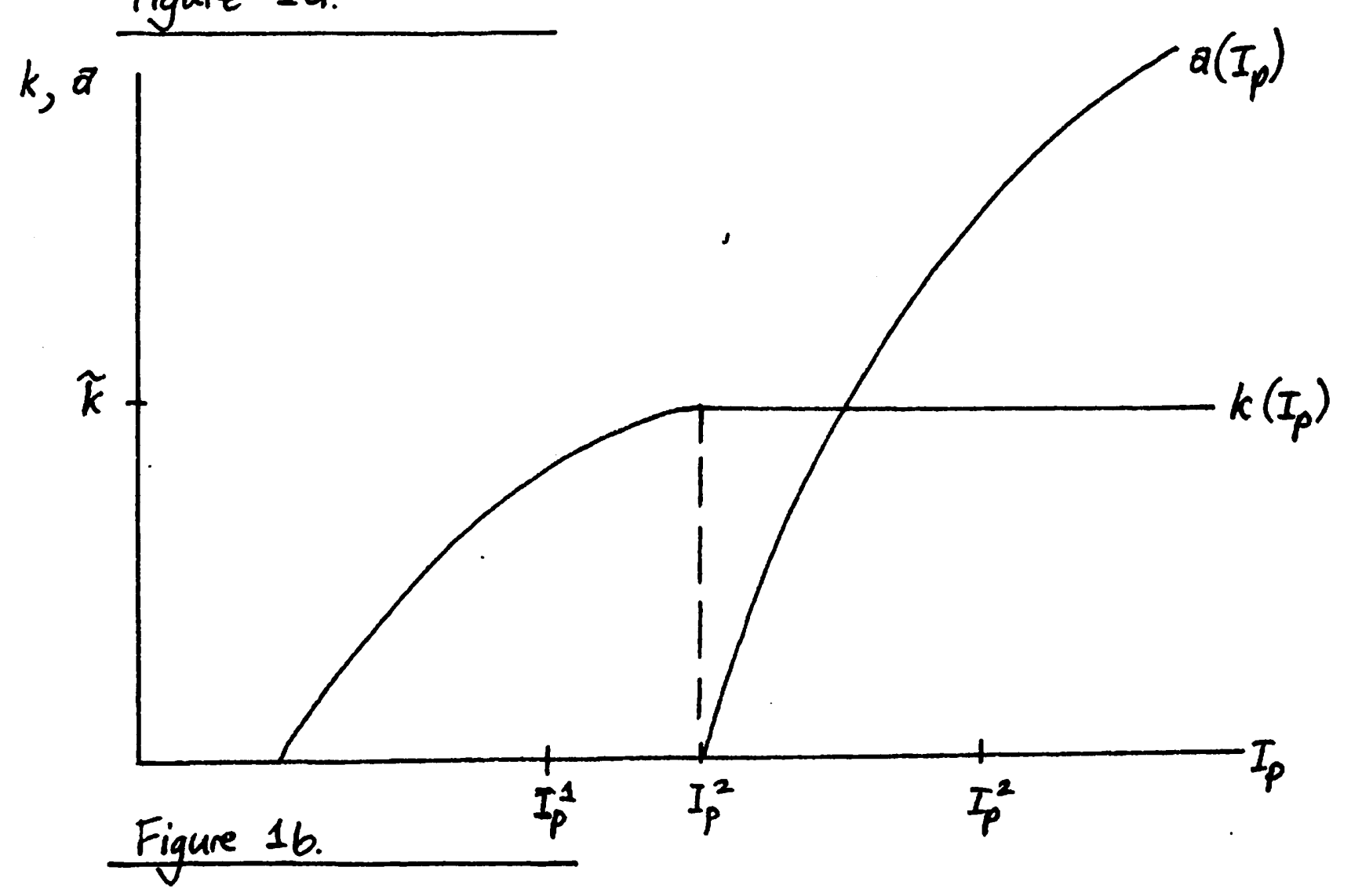


cost of human capital investment is initially below that of asset transfers, resources will be initially transferred via human capital investment, from $\varepsilon_{3}$ to $b_{3}$, for the family with income $I_{p}^{3}$. Beyond that point the marginal cost of human capital investment exceeds that of asset transfers, so that further transfers $\left(b_{3} \rightarrow c_{3}\right)$ are made in the form of material wealth $\left(a_{3}\right)$, in order to achieve the desired per capita consumption of the next generation $\left(z_{c}^{3}\right)$.

The Figure also raises the possibility that desired material wealth transfers may be negative. For suppose parental income is $I_{p}^{1}$. In this case the parent would desire to invest in each child up to point $b_{1}$ and transfer debt to the child so as to reach the consumption point $c_{1}$. Such debt transfers could be effected by partially financing each child's human capital investment through an intrafamily loan, to be repaid either during the parent's lifetime or at decease in the form of a bequest of debt. If such loans were available at constant cost, either internal or external to the family, the level of human capital investment for all households would be independent of the "opportunities" defined by parental income and family size, and would be determined solely by parental efficiency and the child's endowed ability. In the figure, the child's income from human capital would be $\tilde{k}$ for all three households.

However, observation suggests that such equality of opportunity between households does not exist as regards human capital investment, due to the absence of collateral and the high cost of enforcing implicit or explicit loan contracts. In the present model, this 'imperfection' in the capital market is modelled in an extreme form by assuming that all human capital investment is financed internally within the family and neither intergenerational loans nor bequests of debt are permitted (i.e., $a \geq 0$ ). Under this financial liability constraint all human capital investment constitutes an intergenerational transfer. In this context there will exist two categories of families--those 
making transfers on a scale sufficient to make positive wealth transfers, for whom the financial liability constraint is ineffective, and those households who would like to transfer debt to the next generation, but for whom the financial liability constraint is binding.

For households making positive asset transfers, the first order conditions (5) and (6) are appropriate and parental investment in children's human capital is determined by the equality of marginal costs (5). The optimum level of parental inputs (denoted $\tilde{x}$ ) is therefore determined by the condition:

$$
p_{a}[\beta h(\tilde{x}, e)(1-\eta)]=p
$$

This in turn implies that children's income from human capital will be $\tilde{\mathrm{k}}=\beta \mathrm{h}(\tilde{\mathrm{x}}, \mathrm{e}) \tilde{\mathrm{x}}$. This level of human capital income is independent of parental income, family size and the scale of asset transfers and depends only on relative prices, child endowments and household efficiency. Thus for such families, the interaction of quality and quantity dimensions of choice is reflected entirely in transfers of material wealth.

For households for whom the financial liability constraint $(a \geq 0)$ is binding, the first order conditions (5) and (6) require modification to become:

$$
\begin{aligned}
& (5)^{\prime} \frac{\mathrm{U}_{\mathrm{c}}}{\Psi}=\frac{\mathrm{pn}}{\beta \mathrm{h}(\cdot)(1-\eta)} \equiv \pi_{\mathrm{c}}<\mathrm{p}_{\mathrm{a}} \mathrm{n}, \\
& (6)^{\prime} \frac{\mathrm{U}_{\mathrm{n}}}{\Psi}=\mathrm{px}=\frac{\mathrm{pk}}{\beta \mathrm{h}(\cdot)} \equiv \pi_{\mathrm{h}}
\end{aligned}
$$

This latter category of households (located at points such as $b_{0}$ in Figure 1a) will make all transfers in the form of human capital and material wealth transfers will be zero. Since for these households marginal transfers are in the form of human capital investment, the level of such transfers will depend on parental income and family size--determinants of 'opportunities'-in addition to parental efficiency and child endowments. The presence of the financial liability constraint, which is binding on some families but not on 
others, produces differences between families in the response of parent-child transfers to changes in parental income and efficiency, which are examined below (Edwards and Grossman 1977, Tomes 1978a).

The introduction of the financial liability constraint also has consequences for the level of inequality. As a result of this constraint the inequality in human capital investment between households is increased, while inequality in parental consumption is reduced. The effect on the inequality in the consumption of the next generation is ambiguous and depends on the relative magnitude of income and substitution effects. 15

For all households the solutions to the appropriate first order conditions can be represented as a set of demand functions for family size and the consumption of both generations in terms of "family resources" and commodity marginal costs $\left(\pi_{i}^{\prime} s\right)$. These demand functions may be written in general as:

$$
j=f_{j}\left(\frac{s}{\pi}, \frac{\pi_{p}}{\pi}, \frac{\pi_{c}}{\pi}, \frac{\pi_{n}}{\pi}\right) \quad j=z_{p}, z_{c}, n
$$

where S represents "family resources" defined, following Becker and Lewis (1973), as :

$$
S=\sum_{j} \pi_{j} j=I_{p}+\pi_{c} I_{c}
$$

where $\pi$ is a price index of marginal costs $\left(\pi_{i}{ }^{\prime} s\right)$, so that $s / \pi$ represents real family resources, which depend not only on parental income, but also on parental efficiency and child endowments. Other things constant, an increase in eithe $r$ parental efficiency or child endowments raises the resources of the two generation family. Relative marginal costs depend on the levels of commodity outputs, so that these outputs, together with prices $\left(p_{i}{ }^{\prime} s\right)$ and the determinants of family resources, enter the demand functions. 
The demand for the next generation's consumption implies a demand function for the marginal form of transfer as an excess demand for child consumption. For households making positive material wealth transfers, given the utility maximizing level of child consumption $\left(z_{c}^{*}\right)$ implied by $(9)$ and the optimum level of human capital ( $\tilde{k})$, the income-generating function (2) implies the optimum level of asset transfers ( $\left.a^{*}\right)$ :

$$
a^{*}=z_{c}^{*}-e-\tilde{k}=f_{c}\left(\frac{s}{\pi}, \frac{\pi_{p}}{\pi}, \frac{\pi_{c}}{\pi}, \frac{\pi_{n}}{\pi}\right)-e-k\left(\frac{p}{p}, \beta, e\right)>0
$$

where $*$ and $\sim$ denote the optimum levels of the variables. For households making zero asset transfers $\left(a^{*}=0\right)$ the demand for child's consumption implies a demand for human capital investment:

$(11)^{\prime} k^{*}=z_{c}^{*}-e=f_{c}\left(\frac{s}{\pi}, \frac{\pi_{p}}{\pi}, \frac{\pi_{c}}{\pi}, \frac{\pi_{h}}{\pi}\right)-e$

In this latter case the level of human capital investment depends on parental income (via $S / \pi$ ) and family size (via $\pi_{c} / \pi$ ) so that the demand for human capital investment reflects the interaction of quality and quantity dimensions of choice.

\section{COMPARATIVE STATICS}

The comparative statics of the model can now be examined in terms of the demand functions for parental consumption, material wealth and human capital transfers, and family size. Since the joint determination of human capital investment and family size, has been analyzed previously for the case of zero asset transfers (Tomes 1978b), I shall concentrate on the case in which asset transfers are positive.

(i) Parental Income

Since parental income is expected to be a major component of family resources, an increase in income will raise the demand for all superior 
commodities. Hence the consumption of both generations will increase if these commodities are normal.

For households making no asset transfers, the increased demand for the next generation's consumption will be reflected in increased human capital transfers $\left(b_{0}\right.$ to $b_{2}$ in Figure $\left.1 a\right)$. However since this form of transfer is subject to increasing cost, the observed income elasticity of human capital investment will be less than the income elasticity of intergenerational transfers, which holds the cost of such transfers constant. Once human capital transfers have increased to the point where the marginal costs of both forms of transfers are equated (corresponding to parental income $I_{p}^{2}$ ) further transfers take the form of material wealth and the income elasticity of human capital transfers is zero. This is shown in Figure la, where the increase in parental income from $I_{p}^{2}$ to $I_{p}^{3}$ leads to no change in human capital investment $\left(b_{2}\right.$ to $\left.b_{3}\right)$ and the increase in child consumption $\left(b_{2}\right.$ to $\left.c_{3}\right)$ is effected by increased transfers of material wealth. Because typically material wealth transfers constitute only a minor portion of the next generation's total wealth, the income elasticity of asset transfers will be greater than that of child consumption, and will exceed unity if the income elasticity of child consumption is not substantially below the average income elasticity. In addition, since as the scale of material wealth transfers increases, the ratio of material wealth to the total wealth of the next generation declines, the income elasticity of material wealth transfers will be declining as long as the underlying income elasticity of child consumption does not increase dramatically (Becker and Tomes 1976). Further, since material wealth transfers are made subject to constant cost, while the marginal cost of human capital investment is increasing, the income elasticity of transfers in non-human form is predicted to exceed that of human capital transfers. These predictions concerning the relationship between transfers and parental income are shown 
graphically in Figure 1b. Finally, if the income elasticities of child consumption and family size are equal, the income elasticity of asset transfers is predicted to exceed that of child numbers.

\section{Child Endowments}

For households making positive asset transfers, material wealth and human wealth represent substitute modes of intergenerational resource transfer. The demand function (11) implies that material wealth transfers are inversely related to the level of human capital investment. In the present model variations in human capital investment among families making positive asset transfers, reflect differences in either parental efficiency or child endowments .

The effects of increased child endowments on households making positive material wealth transfers, holding parental efficiency constant, are analyzed in Figure 2. An increase in endowed ability has two effects. First, the marginal cost of human capital investment decreases, which leads to the substitution of human capital investment for material wealth transfers in order to achieve any given level of child consumption. (Diagrammatically the slope of the production function $k_{0} \varepsilon_{0}$ increases.) Second, an increase in the endowment of children directly increases the next generation's income and therefore family resources-resulting in an increase in the demand for all superior commodities. (Diagrammatically the endowment point shifts up from $\varepsilon_{0}$ to $\varepsilon_{1}$ ) From Figure 2 it can be seen that, if the household continues to transfer material wealth, human capital investment will be affected only by the substitution effect leading to increased human capital investment $\left(\tilde{k}_{1}>\tilde{k}_{0}\right)$. Conversely, since the marginal cost of child consumption is unaffected, being equal to the unchanged marginal cost of asset transfers, the consumption of the two generations is subject only to an income effect. The consumption of 


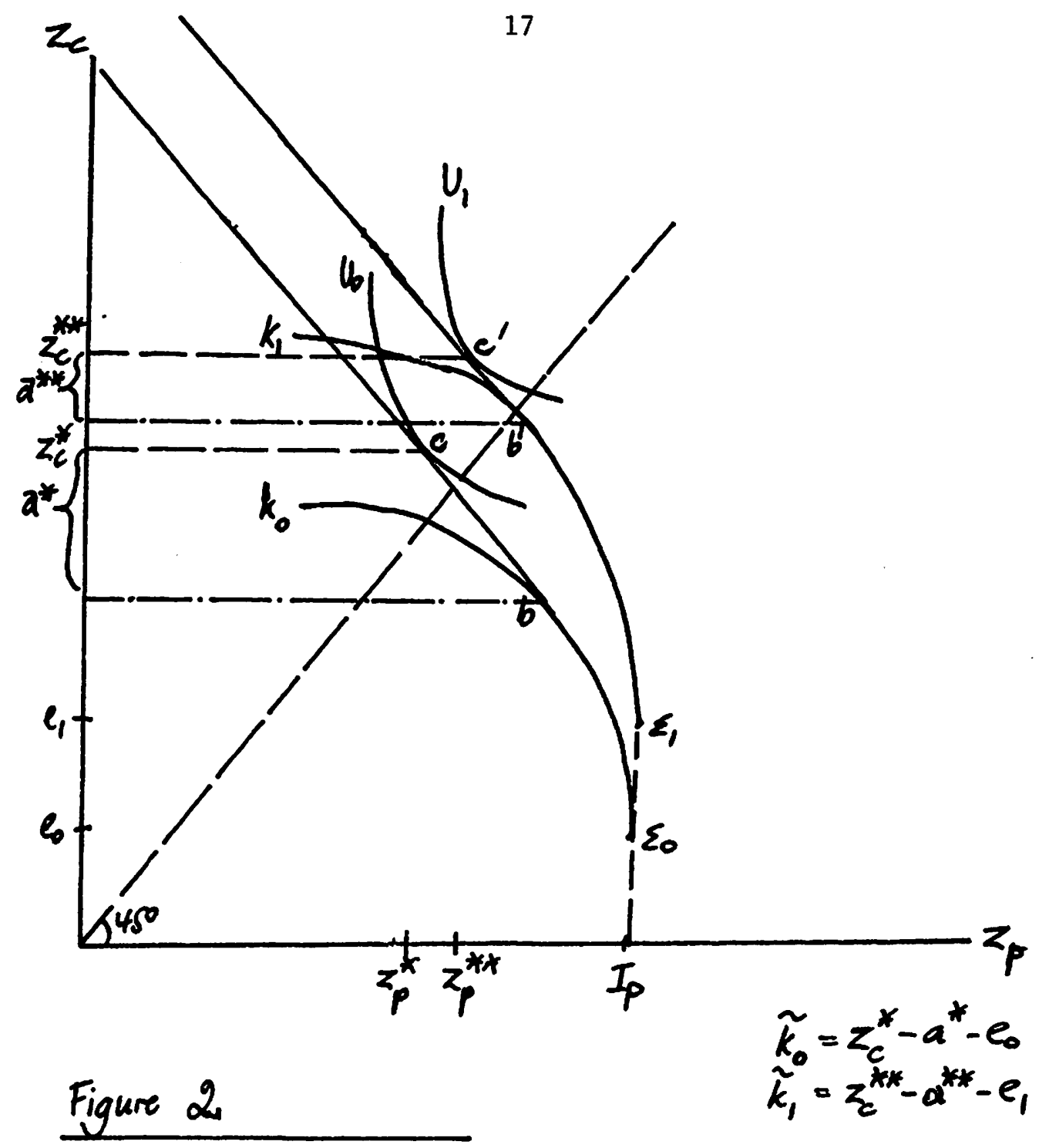


both generations will therefore increase from $c$ to $c^{\prime}$ ).

An operative altruistic motive implies that the consumption of both generations is increased in response to greater child endowments. Since parental income is assumed constant, the increased parental consumption implies (by equation (3)) that total parental expenditures on the next generation are inversely related to child endowments. Therefore the increase in the consumption of children that results from increased endowments is less, when parents adjust the optimal level expenditures, than if parental expenditures remained constant. In this way the redistribution of resources between the generations of the family operates to equalize consumption in the subsequent generation. Within a given parental income stratum,children with low endowed incomes are "compensated" in the form of greater parental expenditures and conversely children with high endowed incomes are "taxed" in the form of reduced parental expenditures, which finance increased parental consumption. Since parental expenditures on human capital investment increase, while total expenditures on the next generation decrease, this implies that the intergenerational redistribution of resources is reflected in material wealth transfers, which are inversely related to child endowments.

When the choice of family size is endogenous, there are additional effects which result from the substitution between quality and quantity, so that in general the relationship between material wealth transfers is ambiguous. However, there is a strong presumption of an inverse relationship. If the utility function is CES with equal elasticities of substitution a sufficient condition for such an inverse relationship is that the next generation's consumption constitute no more than half family resources. 16 This would be the case if the rate of time/generation preference exceeds the difference between the rate of interest and the (endogenous) population growth rate. Hence under these 
assumptions the equalizing role of family intergenerational transfers is reflected in reduced material wealth transfers, which "finance" the increase in parental consumption, associated with increased child endowments. When parental income and efficiency are held constant, all variations in human capital investment reflect differences in endowed ability. The inverse relationship between material wealth transfers and endowments therefore implies a negative relationship between material wealth transfers and child's income from human capital. This important prediction of an inverse relationship between material wealth transfers and the child's income from human capital is subject to empirical investigation in section 4 .

For households making zero asset transfers the effects of an increase in child endowments are more ambiguous. An increase in child endowments directly increases the next generation's income and therefore household resources. This produces an income effect as parents reduce the level of human capital investment, in order to "finance" increased parental consumption. On the other hand, increased endowments reduce the marginal cost of the next generation's consumption which leads to a substitution effect out of parental consumption and into children's consumption, in the form of increased expenditures on human capital. Hence in this case the effects of increased endowments on both parental consumption and the size of human capital transfers are ambiguous and the only clear prediction is that children's consumption will rise. Therefore for households making zero asset transfers, the inequality in child consumption that results from the optimum choice of intergenerational transfers by the family, may be greater or less than the inequality that would result from a fixed level of parental expenditures on children. Although the effect of increased child endowments on human capital investment is ambiguous when asset transfers are zero, one additional prediction 
can be made. If the elasticity of children's human capital with respect to endowments does not exceed unity--the "plausible" case--and all conmodities are superior and equal substitutes, it can be shown (Tomes 1978a, p. 173) that increased child endowments will increase the human wealth of children receiving positive asset transfers, relative to the human wealth of children receiving no material wealth transfers. Hence a uniform \% increase in the endowments of all members of the next generation is predicted to increase the inequality in human wealth in that generation.

\section{(iii) Household Efficiency}

In analyzing the effects of differences in parental efficiency on material wealth transfers--for families making transfers in this form--it is necessary to distinguish between two alternative conceptual experiments, depending on whether the level of human capital investment is being held constant or allowed to vary. In the former case, account should be taken of the fact that the level of human capital investment is the outcome of an optimizing decision (Becker 1967, Rosen 1973). If two individuals are observed to receive the same income from human capital ( $\tilde{k})$, but differ in terms of parental efficiency, the individual from the advantageous background must be disadvantaged in some other respect--otherwise he would not be observed at that income level. In the context of the present model, this disadvantage takes the form of a lower endowment of "ability", which offsets the effects of greater parental efficiency. Thus in the demand function for material wealth transfers, which holds the level of human capital investment constant, the coefficient on parental efficiency will capture the combined effect of an increase in parental efficiency and a compensating decrease in endowed ability, which keeps the level of human capital investment constant. Since family resources and the marginal cost of human capital investment depend on both child endowments and parental efficiency, the relationship between material wealth transfers and 
parental efficiency is ambiguous. Indeed it can be shown that, under some simplifying assumptions, a higher level of parental efficiency (holding human capital investment constant) will lead to greater material wealth transfers and reduced family size. (See equation A9 in the Appendix).

The predictions obtained thus far concerning the structural demand functions for material wealth transfers and family size, which include the level of human capital investment as an argument, may be summarized by writing the demand functions, for households making positive material wealth transfers, (assuming all variables are measured in logs) as:

$$
\left\{\begin{array}{r}
\mathrm{a}=\psi_{0}+\psi_{1}^{(+)} I_{\mathrm{p}}+\psi_{2} \beta+\psi_{3} \mathrm{k}+\psi_{4}^{\mathrm{n}} \\
(+) \quad(-) \\
\mathrm{n}=\delta_{0}+\delta_{1} I_{\mathrm{p}}+\delta_{2} \beta+\delta_{3} \mathrm{k}+\delta_{4} \mathrm{a}
\end{array} \quad \Psi_{1}>\delta_{1}\right.
$$

where the predicted signs are designated above the coefficients, under the assumption that the utility function is homothetic CES and the condition described earlier is fulfilled (see fn. 16). For simplicity the price variables $\left(p_{i}^{\prime} s\right)$ are omitted. Estimates of these structural equations are presented in Section 4.

In the alternative comparative static exercise, the scale of human capital investment adjusts in response to'changes in parental efficiency. The results of an increase in parental efficiency in the non-market production of human capital, holding parental income and child endowments constant, are illustrated in Figure $3 \mathrm{a}$. For households who continue to make positive material wealth transfers the marginal costs of consumption of the two generations are unaffected. However since the marginal costs of intramarginal units of intergenerational transfer in the form of human capital are reduced, the resources of the family are increased. As a result of this income effect the consumption of both generations increases (from point $c$ to $c^{\prime}$ ). 

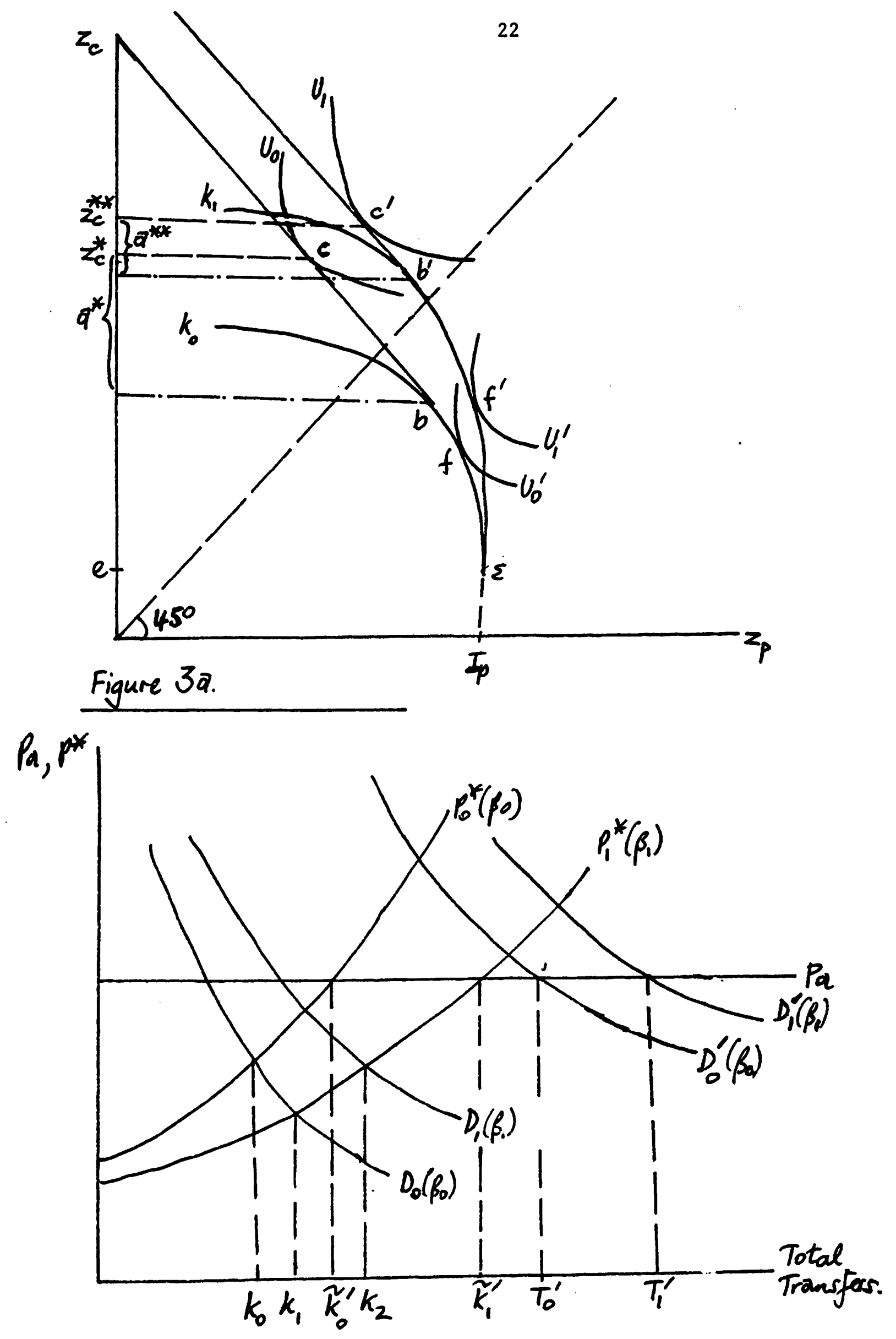

Figure 36 . 
As before the increased consumption of parents is financed by reduced expenditures on children, so that the increase in child consumption is partially offset by the within-family intergenerational redistribution of resources. The resulting inequality in child consumption is therefore less than the inequality that would occur if parental expenditures were constant. Since marginal transfers are in the form of material wealth, they are predicted to be inversely related to the level of parental efficiency. There is in addition a substitution effect. Since the marginal cost of human capital decreases with greater parental education, more transfers are made in this form (i.e., the point $b^{\prime}$ is to the left of point $b$ ), which also reduces the scale of asset transfers. Intuitively, since parents with greater stocks of human capital are assumed to be more efficient at investing in their children's human capital, they will substitute towards this form of transfer. Since all households face the same rate of return on assets, parents that are relatively inefficient in the production of human capital will choose a material-wealth-intensive mode of intergenerational resource transfers. Hence because of both the "redistribution effect", and the substitution of human capital investment for transfers of material wealth, asset transfers are predicted to be inversely related to parental efficiency.

The endogenous choice of family size, and the resulting "qualityquantity" interaction produces additional effects, so that in general the relationship between asset transfers and parental efficiency is ambiguous. However, under the assumptions that the parents utility function is homothetic CES with equal elasticities of substitution between all comodities, and that the rate of time/generation preference exceeds the interest rate net of the population growth rate, the predictions derived above continue to apply. Thus under these circumstances asset transfers are predicted to be inversely 
related to parental efficiency (see Appendix, equation A10 and the related discussion).

Under the maintained hypothesis concerning the utility function, the results of the comparative static exercise, which does not hold the level of 'human capital investment constant, can be summarized in terms of a second set of demand functions. For households making positive asset transfers these demand functions can be written (assuming all variables are measured in logs) as :

$$
\left\{\begin{array}{c}
(+) \stackrel{(-)}{(-)}(-) \stackrel{(-)}{\alpha_{0}}=\alpha_{0}+\alpha_{1} I_{p}+\alpha_{2} \beta+\alpha_{3} e+\alpha_{4}^{n} \\
(+) \quad(?) \quad(?) \quad(-) \\
n=\lambda_{0}+\lambda_{1} I_{p}+\lambda_{2} \beta+\lambda_{3} e+\lambda_{4}^{a}
\end{array}\right.
$$

Consider now the effects of differences in parental efficiency amongst families making no transfers of material wealth. For such households the level of human capital investment will be influenced by both income and substitution effects, as greater parental efficiency is associated with greater family resources and a lower marginal cost of the next generation's consumption. As a result children's consumption will be greater (corresponding to $f^{\prime}$ instead of $f$ in Figure $3 a$ ) as a result of a larger income for human capital. Parental consumption may increase or decrease depending on the relative magnitude of income and substitution effects. Since parental expenditures may either increase or decrease, the optimal adjustment of parent-child transfers may either reinforce or offset the change in child consumption that would result from a fixed expenditure on children's human capital.

As before it is useful to contrast the effects of differences in parental efficiency on human capital investment, in the two regimes, according 
to whether asset transfers are positive or zero. This is done in Figure $3 b,{ }^{17}$ which conveys the relevant information from Figure $3 a$. In the figure the horizontal axis measures the income the child derives from parental transfers, $p_{a}$ represents the constant marginal cost of asset transfers and $p^{*}$ the increasing marginal cost of human capital investment, which depends on the level of parental efficiency. Families making positive asset transfers invest in their children's human capital up to $\tilde{\mathrm{k}}_{0}^{\prime}$ and thereafter transfer $\mathrm{T}_{0}^{\prime}-\tilde{\mathrm{k}}_{0}^{\prime}$ in the form of material wealth. For these households greater parental efficiency results in a substitution effect, reflected in increased human capital transfers from $\tilde{\mathrm{k}}_{0}^{\prime}$ to $\tilde{\mathrm{k}}_{1}^{\prime}$ (corresponding to $\mathrm{b}$ and $\mathrm{b}^{\prime}$ in Figure $3 \mathrm{a}$ ) and an income effect due to the increased demand for child consumption, from $\mathrm{T}_{0}^{\prime}$ to $\mathrm{T}_{1}^{\prime}$ reflected in greater asset transfers (corresponding to $c$ and $c^{\prime}$ in Figure 3a).

For families not making material wealth transfers, with demand curves such as $D_{0}$, all transfers are in human form. Amongst such families, greater parental efficiency is associated with a substitution effect (from $k_{0}$ to $k_{1}$ ) and an income effect from $k_{1}$ to $k_{2}$, both of which result in increased human capital transfers (associated with a move from $f$ to $f^{\prime}$ in Figure 3a). Since for households transferring material wealth, human capital represents the intra-marginal form of transfer, the substitution effect is along an infinitely elastic demand curve corresponding to $\mathrm{p}_{\mathrm{a}}$, and therefore exceeds the substitution effect for households where marginal transfers are in human form. Consequently, the difference in the magnitude of response--depends on whether the substitution effect for families transferring material wealth, is greater than the (sma1ler) substitution effect plus the income effect for households making transfers exclusively in the form of human capital. It can be shown (Tomes 1978a, pp. 172-173) that if the utility function is homothetic CES, all commodities are 
equally substitutable and the rate of time/generation preference is sufficiently large, the response of human capital investment will be greater among households making positive asset transfers. Thus under these conditions, a uniform increase in parental productivity--say due to the secular increase in education-would be associated with increased inequality in human wealth in the subsequent generation.

The results of the comparison of the response of human capital investment to differences in income, child endowments, household efficiency and family size, according to whether asset transfers are positive or zero can be summarized by writing the two demand functions for the two categories of families :

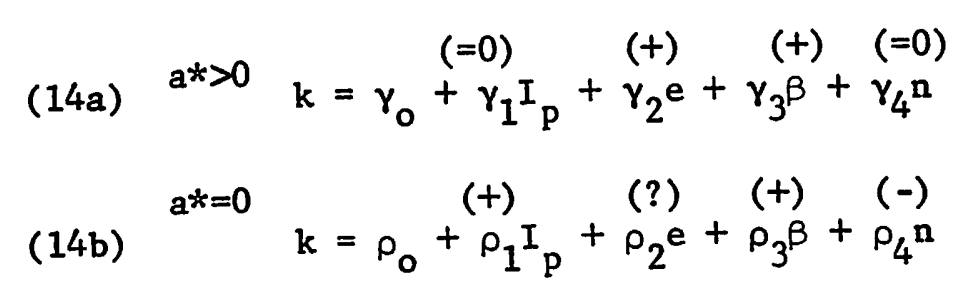

Given the assumptions concerning the utility function the model predicts the following inequalities:

(14c) $\rho_{1}>\gamma_{1}=0, \gamma_{2}>\rho_{2}, \gamma_{3}>\rho_{3}, \rho_{4}<\gamma_{4}=0$

These predictions are subject to empirical test in section 4.

THE REDUCED FORM DEMAND FUNCTIONS

The demand functions for asset transfers and numbers for households making positive asset transfers (13) can be solved simultaneously for the reduced form demand functions: 


$$
\text { (15) }\left\{\begin{aligned}
a= & {\left[1-\alpha_{4} \lambda_{4}\right]^{-1}\left\{\left(\alpha_{0}+\alpha_{4} \lambda_{0}\right)+\left(\alpha_{1}+\alpha_{4} \lambda_{1}\right) I_{p}+\left(\alpha_{2}+\alpha_{4} \lambda_{2}\right) \beta+\left(\alpha_{3}+\alpha_{4} \lambda_{3}\right) e\right\} } \\
= & (+)(?-)(?-) \\
n= & {\left[1-\phi_{1} I_{p}+\phi_{2} \beta+\phi_{3}\right]^{-1}\left\{\left(\lambda_{0}+\lambda_{4} \alpha_{0}\right)+\left(\lambda_{1}+\lambda_{4} \alpha_{1}\right) I_{p}+\left(\lambda_{2}+\lambda_{4} \alpha_{2}\right) \beta+\left(\lambda_{3}+\lambda_{4} \alpha_{3}\right) e\right\} } \\
& (?)(?)(?) \\
= & \zeta_{0}+\zeta_{1} I_{p}+\zeta_{1} \beta+\zeta_{3} e
\end{aligned}\right.
$$

Greater ambiguity attaches to the predictions concerning the reduced form demand functions. Even with the maintained hypothesis concerning the utility function, the only unambiguous predictions relate to the income elasticity of material wealth transfers. This income elasticity is predicted to be positive. Further it is shown in the appendix, that if the reduced form income elasticity of family size is negative, the reduced form income elasticity of material wealth transfers will exceed the corresponding structural income elasticity (i.e., $\phi_{1} \gtreqless \Psi_{1}$ as $\zeta_{1} \lessgtr 0$, see equation Al3 in the appendix).

One additional assumption yields additional predictions. If returns to scale in the production of human capital do not exceed $1 / 2^{18}$ (i.e., $(1-\eta) \leq 1 / 2$ ), it can be shown that asset transfers are negatively related to both parental efficiency and child endowments [i.e., $\phi_{2}<0, \phi_{3}<0$ (Tomes 1978a, pp. 180182)]

Turning to the reduced form equation for family size it can be seen that, although the structural income elasticity of demand for numbers is predicted to be positive, the reduced form income elasticity may take on either sign. Numbers of children could therefore appear to be an inferior commodity in terms of the reduced form demand for numbers, while at the same time family size enters the utility function with an income elasticity equal to that of all other commodities. This possibility results from the 
fact that since an increase in parental income is predicted to result in a greater percentage increase in asset transfers than in numbers, this raises the marginal cost of numbers relative to that of child's consumption. If the induced substitution effect outweighs the income effect, the observed relationship between numbers and parental income will be negative, implying that numbers of children are apparently an inferior commodity. The coefficients of parental efficiency and child endowments in the reduced form demand function for family size are again ambiguous in sign. Empirical estimates of the reduced form demand functions for material wealth transfers and family size are presented in Section 4.

\section{EMPIRICAL SPECIFICATION}

In moving from the theory to the empirical specification of the model, two points require discussion. First, the theoretical model developed in the previous section assumed both perfect foresight and certainty. Under these conditions individuals face a single allocation problem at the commencement of their tenure as parents and have neither the desire, nor need to revise their decisions in the course of their lifetime. However, in the real world both certainty and perfect foresight are lacking. Therefore, based upon their future expectations parents determine their fertility, the level of human capital investment and material wealth transfers, with the possibility of revision if realized outcomes diverge from their expectations. Given the typical family life cycle in which completed fertility is determined prior to the completion of investment in the human capital of children and material wealth transfers may occur at any time until the decease of the parents, these decisions are subject to revision to differing degrees. In addition human capital 
investment may be completed before the child's income-earning ability becomes known to either generation, since that ability may be subject to stochastic influences such as the occurrence of ill-health and disability. Or to give another example, a sizeable inheritance received by a son (or daughter)-in-1aw, may raise the child's income above the level anticipated by parents. Given that the parent's fertility is predetermined and given the precommitment of human capital investment, no adjustment of these choice variables may be possible or desirable. However, the level of material wealth transfers may be adjusted in the light of such events. In the empirical specification of the model I view the dependent variables as jointly determined. However, uncertainty and the temporal ordering of events suggest the introduction of variables which measure the realization of events which occur over the life cycle.

Second, although the theory derives predictions concerning the total transfers of material wealth to the next generation, these transfers may occur as gifts during the parental lifetime, as benefits from life insurance contracts or as a bequest at the decease of parents. Data on gifts are notoriously difficult to obtain and the data set I use does not contain this information. However, the omission of information on gifts presents less of a problem for the present study which employs data on small wealth-1eavers. In these data there is 1ittle tax incentive in favor of gifts over bequests. 19 In addition the prospect of unanticipated changes in the lifetime income of both children and parents creates an incentive to defer material wealth transfers until the parents decease. The inheritance received by the child is therefore used as a measure of material wealth transfers. 
THE DATA

The data used in this study derive from a 5\%. random sample of 659 estates probated in the Cleveland, Ohio area in 1964-65 [Sussman, et al., 1970]. Surviving kin and other heirs were interviewed, including 657 sons and daughters of the decedents. Information was obtained on the total estate, usual occupation, education and other characteristics of the deceased and on the inheritance, income, education and other characteristics of the surviving kin. The principal variables are briefly described here and defined, together with other variables, in Table 1.

No direct measure of the annual or lifetime income of the decedent is available. However, information on the "permanent characteristics" of the decedent is available. Given supplementary data on income and the same set of characteristics from another source, a predicted income variable for decedents could be constructed. The subsample of the surviving kin of these estates was used for this purpose. First, the income of recipients was regressed on their permanent characteristics; then the estimated coefficients, together with the corresponding permanent characteristics of the decedent, were used to construct a measure of the decedent's "permanent" income. The education of the decedent was used as a measure of parental efficiency. When parental income (and hence "market efficiency") is held constant, a higher level of parental education is interpreted as implying a greater level of non:market efficiency. Additional characteristics of the decedent (age, sex, race, religion, origin (birth place) and marital status), and of the recipient (age, sex, marital status and number of individuals employed in recipient's family) were included. Some of these variables hold constant life cycle factors (e.g., age), while others may be interpreted as crude measures of some 
TABLE 1: DEFINITION OF VARIABLES

\section{Sample of A11 Children}

Theoretical

Varlable

Material Wealth

Transfers

Human Capital

Inves tment

Family Size

Parental Income

Parental

Efficiency

Additiona1

Parent

Characteristics :

Empirical Measure

Mneumonic

Inheritance received by son/daughter $\left(\$ 000^{\prime} s\right)^{4}$

INHR

Annual Family Income of son/daughter ${ }^{2}$ ( $\$ 00$ 's)

Years of Schooling of son/daughter

INCOMER ${ }^{+}$

SCHR

Total Number of kin of Decedent

TNKIN

Constructed Measure of Decedent's "permanent" Income ${ }^{3}$ (\$00's)

INCOMED ${ }^{+}$

Years of Schooling of Decedent

SCHD

Interaction between SCHD and sex of decedent

(female $=1$, male $=0$ )

SCHD. SEXD

Race of Decedent (White $=2$ Nonwhite $=1$ )

Sex of Decedent (Female $=2$, Male $=1$ )

RACE

SEXD

AGED

Age of Decedent

AGEDSQ

Age of Decedent Squared

Interaction between age and schooling of decedent

Marital status of Decedent at death: Married, divorced

(omitted category--widowed or single)

Religion of Decedent: Jewish, Protestant, Catholic

(omitted category: No religion, Eastern Orthodox)

Origin of Decedent: Birthplace in US, Western Europe, (omitted category: Birthplace Eastern Europe or other) Number of kin of decedent, other than children

AGED · SCHD

\{MARRIEDD

DIVCD

(JEWD

PROTD

CATHD

SORIGINUS

LORIGINWE

OTHERKIN

Additional

Sex of recipient (Female $=2, \mathrm{Male}^{\prime}=1$ )

SEXR

Age of recipient

Age of recipient squared

Marital Status of Recipient: Single, divorced or

Separated (omitted category: Married)

Number of Household members employed

Dummy variable for the presence of non-labour income:

(1: positive non-1abour income, 0: zero non-1abour income)

Sex of "breadwinner" in recipient's household

AGER

AGERSQ

$\int$ SINGLER

LIV/SEPR

NEMPLR

NLABINC

SEX 
Notes to Table 1:

1. + designates variable entered in natural logarithm.

2. The reported monthly family income, which was originally coded in categories was recoded on an annual basis using interval mid-points for the closed intervals and using the (estimated) mean of a Pareto distribution for the open-ended interval.

3. The income of recipients INCOMER (for those reporting a positive family income) was regressed on a set of "permanent" characteristics of recipients. The estimated coefficients were:

$$
\begin{aligned}
\text { INCOMER }^{+}= & 3.915-0.325 \text { SCHR }+0.01 \text { AGER SCHR }-0.104 \text { AGER }+0.0002 \text { AGERSQ } \\
& +0.266 \text { OCCR }+0.302 \text { NEMPLR }-0.093 \text { SEX }+0.627 \text { RACE }+0.494 \text { ORIGINWE } \\
& +0.658 \text { ORIGINUS }+0.320 \text { ORIGINEE }+0.668 \text { PROT }+0.539 \text { CATH }+1.278 \mathrm{JEW} \\
& \mathrm{R}^{2}=0.216 \quad \mathrm{n}=608 \\
& \text { where ORIGINEE }=1 \text { if recipients origin is Eastern Europe, } 0 \text { otherwise; } \\
& \text { OCCR is a seven category occupation of "breadwinner" code (coded from 1: } \\
& \text { unskilled, to } 7: \text { executive) }
\end{aligned}
$$

These coefficients, together with the corresponding characteristics of the decedent were used to construct the income variable INCOMED (NEMPL was set equal to unity).

4. In the original data the child's inheritance is coded in $\$ 000$ intervals. An inheritance of less than $\$ 500$ is therefore coded as zero. The model has been reestimated with the 1 imit value of $\$ 250$ (i.e.,.250)--the results are unchanged. 
dimensions of the child's endowment. However, these data lack a comprehensive measure of the child's endowed income, or even a measure of "ability", such as IQ. This raises the problem of omitted variable bias. However, in the set of structural equations (12), the level of human capital investment represents a measure of the child's endowment, so that the absence of direct measures of the child's endowment does not pose a serious problem in this context.

The empirical measures of the endogenous variables were defined in the following manner: The reported total number of kin was used as a measure of family size. Since this measure includes kin in addition to children, the number of these more distant kin was also included as a control variable. The level of schooling is the most frequently used measure of human capital investment. However, this variable corresponds to an "input" measure of human capital investment, ${ }^{20}$ rather than the "output" measure suggested by the theory, which is the income of the child attributable to parental transfers. In addition schooling represents a decision variable determined early in the life cycle, whereas income represents the return to skills and other sources of income realized at a later stage in the life cycle. Life cycle considerations suggest that family size may depend on children's schooling, whereas the material wealth transfer received by the child may be more closely related to the child's realized income than the child's schooling. In the light of this, both the child's reported family income ${ }^{21}$ and schooling are used as measures of human capital investment and the empirical model is augmented by an income equation relating these two variables. 
As indicated earlier, the inheritance received by the child is used as a measure of material wealth transfers. The observed distribution of inheritances is truncated at zero- $-41.5 \%$ of sons and daughters reported receiving a zero inheritance from the decedent's estate. For this reason a Tobit procedure is employed in regressions using the whole sample. In addition this property permits a test of the "two-regime" model in which the determinants of human capital investment are predicted to differ according to whether material wealth transfers are.zero'or positive. Finally, in accordance with the previous discussion, life cycle factors suggest certain identifying restrictions. Thus the marital status of the decedent at death--the presence or absence of a surviving spouse--is assumed to influence only the inheritance and to have no independent effect on the remaining endogenous variables. Also, the marital status of the recipient (divorced or separated, married or single) enters the schooling, income and inheritance equations, but is excluded from the family size equation. It was also assumed that the catholic/non-catholic religious affiliation of the decedent has a direct effect on completed family size, but no direct effect on the remaining choice variables. In addition, the Jewish/non-Jewish status of the decedent was assumed to have no direct influence on family size, but was permitted to influence material wealth transfers. 22

4. EMPIRICAL RESULTS

Table 2 reports estimates for the sample as a whole. Line 1 reports the Tobit estimate of the inheritance equation, while line 2 reports the corresponding 3 SIS estimate. The qualitative results are the same, but since the latter does not take account of the truncation of the dependent variable I sha11 concentrate on the Tobit estimate. 


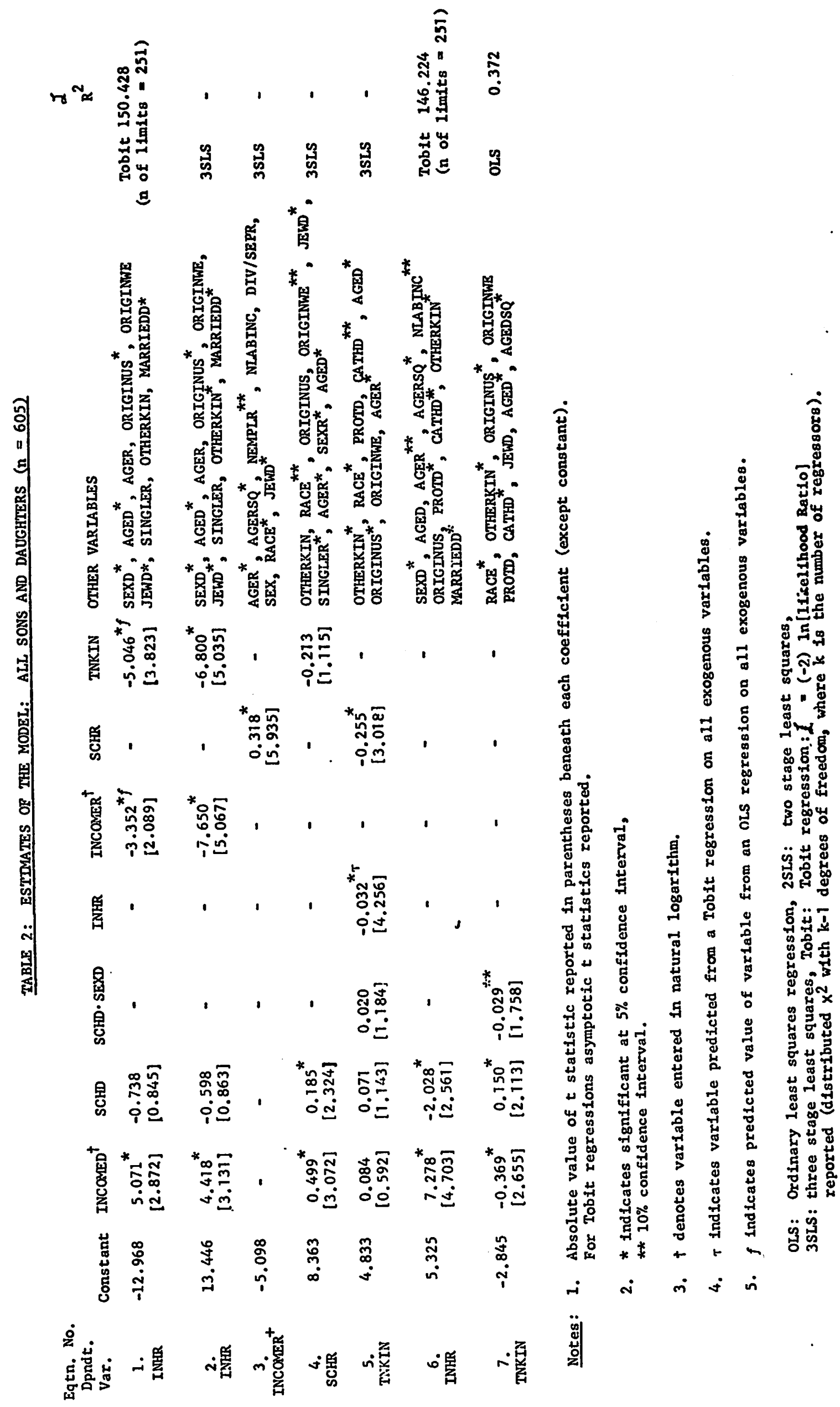


In the Tobit inheritance equation the decedent parent's income enters with a significant positive coefficient--implying an income elasticity of 1.22 at the mean--a value not significantly different from unity. The income of the recipient enters the inheritance equation with a significant negative coefficient--a result which contrasts with the findings of previous studies using these data ${ }^{23}$ (Brittain 1978, p. 45). This latter result offers strong confirmation for the existence of an operative altruistic bequest motive, and is consistent with the prediction that inherited material wealth serves as a means of redistributing resources between the generations of the family. The elasticity of inheritance with respect to the recipient's income is -0.81 at the mean. A $10 \%$ increase in the incomes of both generations is therefore predicted to increase material wealth transfers by $4 \%$. Parental schooling has no direct effect on the size of the child's inheritance, when child's income is held constant. Lastly, the total number of kin--the empirical measure of family size--enters the inheritance regression with a significant negative coefficient, consistent with the existence of substitution between family size ("quantity") and the per capita bequest ("quality").

Line 3 relates the $\log$ of the recipient's family income to the recipient's schooling and indicates a sizeable marginal effect of schooling on income. ${ }^{24}$ The schooling equation is 'reported in line 4. The decedent's income enters significantly, implying a small income elasticity of 0.04 , at the mean level of schooling, a finding that is consistent with the existence of imperfect capital markets for the finance of human capital investment. Parent's schooling enters with a significant positive coefficient, with each additional year of parent's schooling being associated with an increment of approximately two months in the child's schooling. Finally, children's schooling is independent of family size. 
Estimates of the family size equation are reported in 1 ine 5 , where the dependent variable is the total number of kin of the decedent. In this regression neither parents income nor education enter significantly. For the sample as a whole there is thus no evidence of a positive income elasticity of family size. Both the child's schooling and inheritance enter with significant negative coefficients. Concerning the coefficient of children's schooling in the family size equation we have derived no unambiguous prediction. However, the negative coefficient on the child's inheritance 25 is consistent with the predicted quality/quantity tradeoff.

The last two lines of Table 2 present estimates of the reduced form equations for the child's inheritance and family size. The reduced form inheritance equation (1ine 6 ) was estimated using the Tobit technique. In this equation the income elasticity of inheritance is 1.75 , evaluated at the mean of the dependent variable--a value that is significantly different from unity at the $5 \%$ leve1. The decedent's schooling enters the reduced form inheritance regression with a significant negative coefficient. This finding is consistent with the pre-diction that more educated parents invest more in their children's human capital (see line 4), and as a consequence make smaller bequests of material wealth. The parameter estimate implies that each additional year of decedent's schooling reduces the child's inheritance--by just over $\$ 2000-$ a sizeable effect in relation to the average inheritance of $\$ 4,154$. The reduced form equation of family size is reported in line 7 . In contrast to the structural equation (line 5), parental income enters with a significant negative coefficient, implying an income elasticity of -0.09 at the mean of the dependent variable. In addition parental education enters the family size equation with a significant positive coefficient. For male decedents an additional year of schooling has a marginally greater effect on family size than for females. These results concerning the re- 
duced form relationship of family size to parental income and schooling may be interpreted as resulting from the substitution between quality and quantity. Other things constant parents with higher income or lower education make greater transfers of material wealth to their children (line 6). As a result such parents face a greater expected cost of additional children and therefore choose a smaller family size.

The estimates presented in Table 2 use the whole sample and therefore pool families where children inherit material wealth with those that receive a zero inheritance. In Table 3 the sample is partitioned in order to analyze differences between these two categories of households. Since the selfselection of households into either category results in the possibility of sample selection bias, the correction procedure developed by Heckman (1976b, 1979) was implemented. This procedure involves initially computing an additional variable--"lambda"--from the probit equation of the selection rule and including this "omitted" variable in subsequent regressions using the selected sample. Table 3 reports the results obtained using 3SLS. 26

Lines 1-8 report results for children who received a positive bequest. The estimates of the inheritance regression duplicate quite closely those for the whole sample (Table 2, line 1). Parenttal income and recipient income enter with the predicted positive and negative signs, with elasticities (at the mean) of 0.98 and -0.46 , respectively. However, in contrast to the previous result parental education enters with a significant negative coefficient.

Although the semi-log specification may be preferable on the a priori grounds that it embodies the prediction of a decreasing income elasticity, the constant elasticity formulation was also estimated (line 5). The estimates show that the major qualitative results are not dependent on the use of the semi-log functional form. 


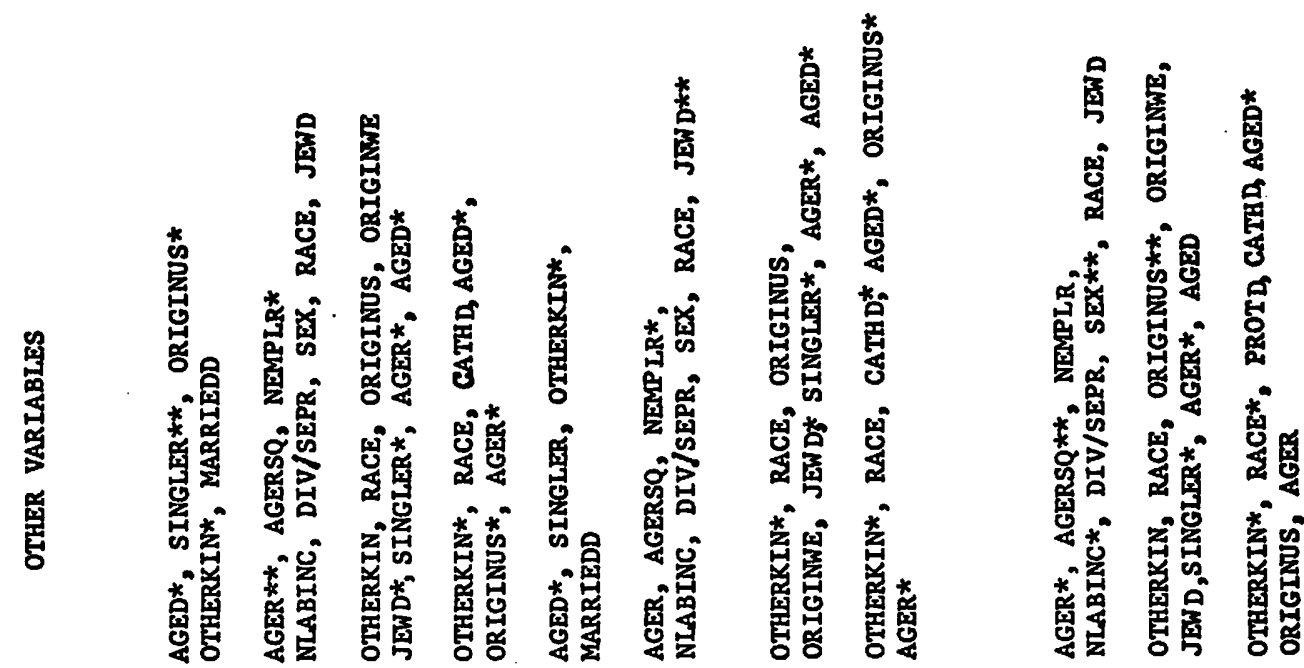

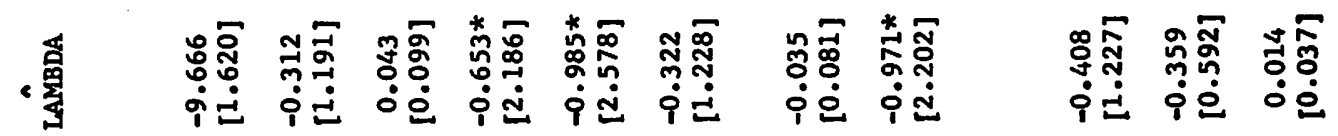

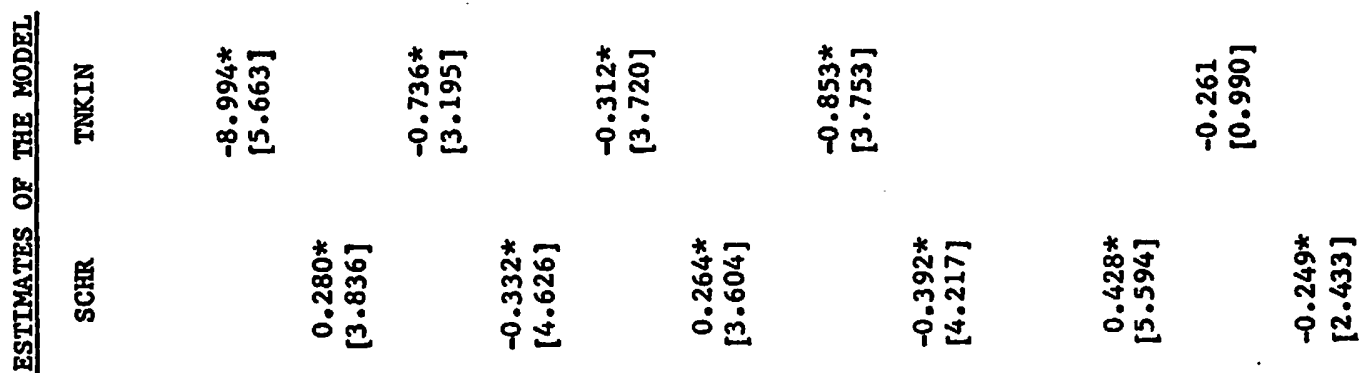

.

兽

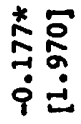

展

*ัँ

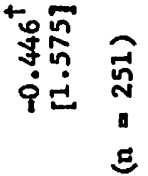

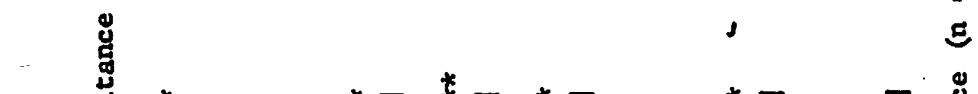

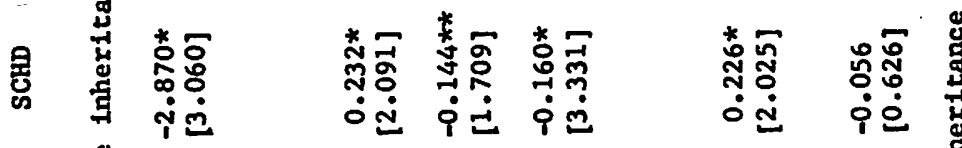

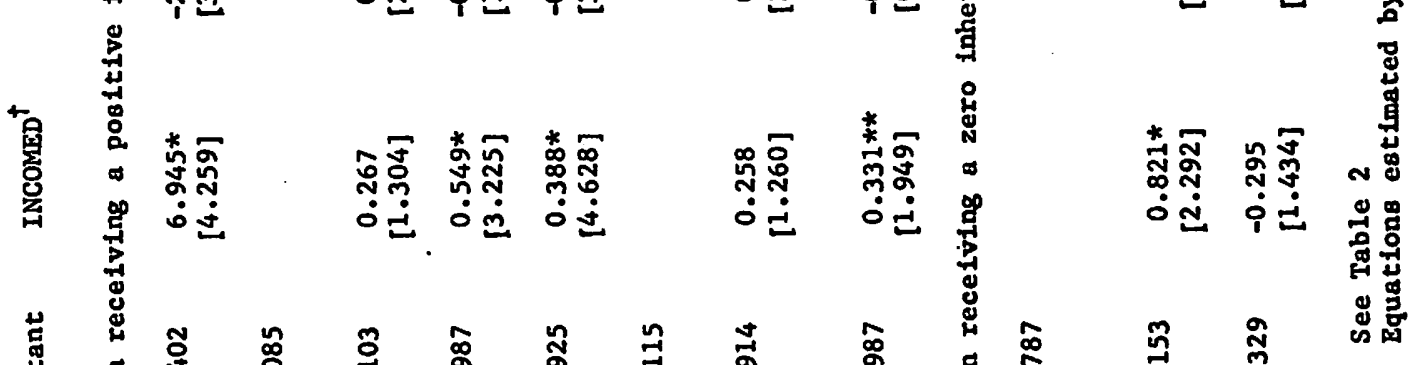

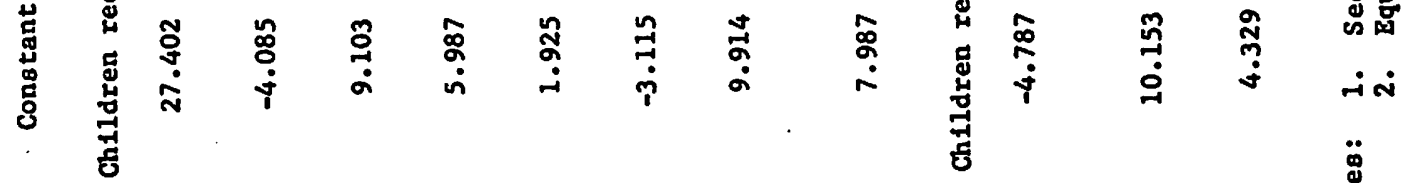

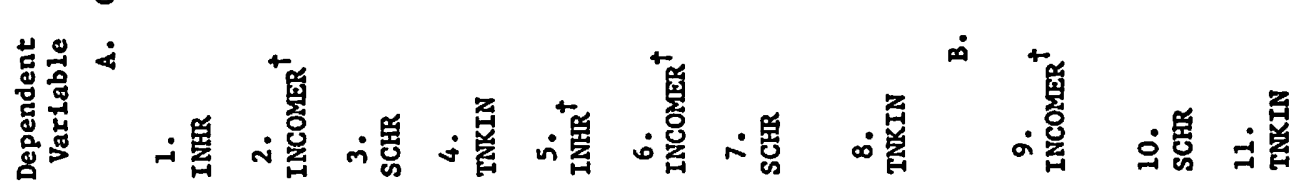


The major question to be addressed in Table 3 is whether the determinants of human capital investment differ between households according to whether material wealth transfers are positive or zero. A comparison of the schooling regressions for the two subsamples, (1ines 3 and 10) indicates differences which are in the predicted direction. For children receiving a positive inheritance, the level of schooling is unrelated to parental income and positively related to parental education. In contrast for children who received a zero inheritance, the level of schooling depends on parental income (with an income elasticity of 0.065 ), but is unrelated to parental education. Thus the 'opportunities' (parental income) are important for households making zero material wealth transfers, while parental education (one determinant of 'ability') is more important for households making positive material wealth transfers. However, contrary to the theoretical prediction, the family size variable (TNKIN) enters with a significant negative coefficient in lines 3 and 7 , for the subsample receiving a positive inheritance, but is not significant for the subsample who do not inherit (1ine 10).

The family size regressions also differ between the two subsamples (lines 4 and 11), although concerning these differences $I$ have obtained no unambiguous predictions. For families making positive asset transfers (1ine 4) the parental income variable is positive and significant--the only evidence in these data of a positive income elasticity of family size. Parental education enters with a negative coefficient which is significant at the $10 \%$ level. In contrast, for the subsample receiving a zero inheritance (line 11) the parental income variable is negative and not significant, while parental education enters with a significant positive coefficient. These results underline the complexity and ambiguity of the relationships between family size and parental income and education. The one result common to both subsamples is that measures of child quality (the child's inheritance and/or schooling) enter 
with significant negative coefficients in the family size equations, consistent with the existence of a quality-quantity tradeoff.

\section{ADDITIONAL RESULTS:}

A major finding of the foregoing analysis is that, holding parental income and education constant, children with higher incomes receive a smaller inheritance of material wealth. This is consistent with the theoretical prediction that parents respond to differences in the ability of children by reducing transfers to children in order to finance greater parental consumption. In this way parents share in the returns to greater child endowments. However, an alternative interpretation is that the observed inverse relationship between inheritance and children's income reflects (partly or entirely) the role of inheritance in compensating for differences between siblings, rather than between parents and children. Thus if parents bequeath more to the child with the lowest income and less to his advantaged sibling this also implies an inverse relationship between inheritance and children's income.

This issue can be addressed using data on 137 families for whom information is available on more than one child. In this subsample $41.6 \%$ of heirs (siblings) received exactly equal shares. However, this figure incliddes easess in : vhich all heirs received the limit value of zero, and therefore by definition inherited equally. Excluding such cases, $21.1 \%$ of heirs inherited exactly equal shares and the vast majority of heirs (78.9\%) received inequal shares in the parental estate. However, some of these between sibling differences are small: $50.4 \%$ of heirs received approximately equal shares--within $\$ 500$ of the average inheritance received 
by children. Nonetheless, the fact that strictly equal division is not the rule in this sample, ${ }^{27}$ suggests that the possibility inheritance is equalizing between siblings warrants further investigation.

Table 4 reports the results of Tobit regressions for subsamples for whom information is available on multiple heirs. In these regressions both the mean income of children and the deviation of the child's income from the family mean are introduced as determinants of inheritance. The latter variable is predicted to enter with a negative coefficient if disadvantaged children receive larger shares in the parental estate. This variable enters with the predicted sign, but never attains statistical significance. In contrast the mean income of children enters with a significant negative coefficient. Thus, holding income inequality between children constant, the higher the average income of children the lower the inheritance received by children. These results suggest that the inverse relationship between recipients' income and inheritance reflects for the most part a reallocation of resources between the generations of the family.

These results for the subsample for which information is available on multiple-heirs, and also those for the subsample with information on both the decedent and surviving spouse ${ }^{28}$ (not reported here), confirm the results reported earlier for the whole sample. 


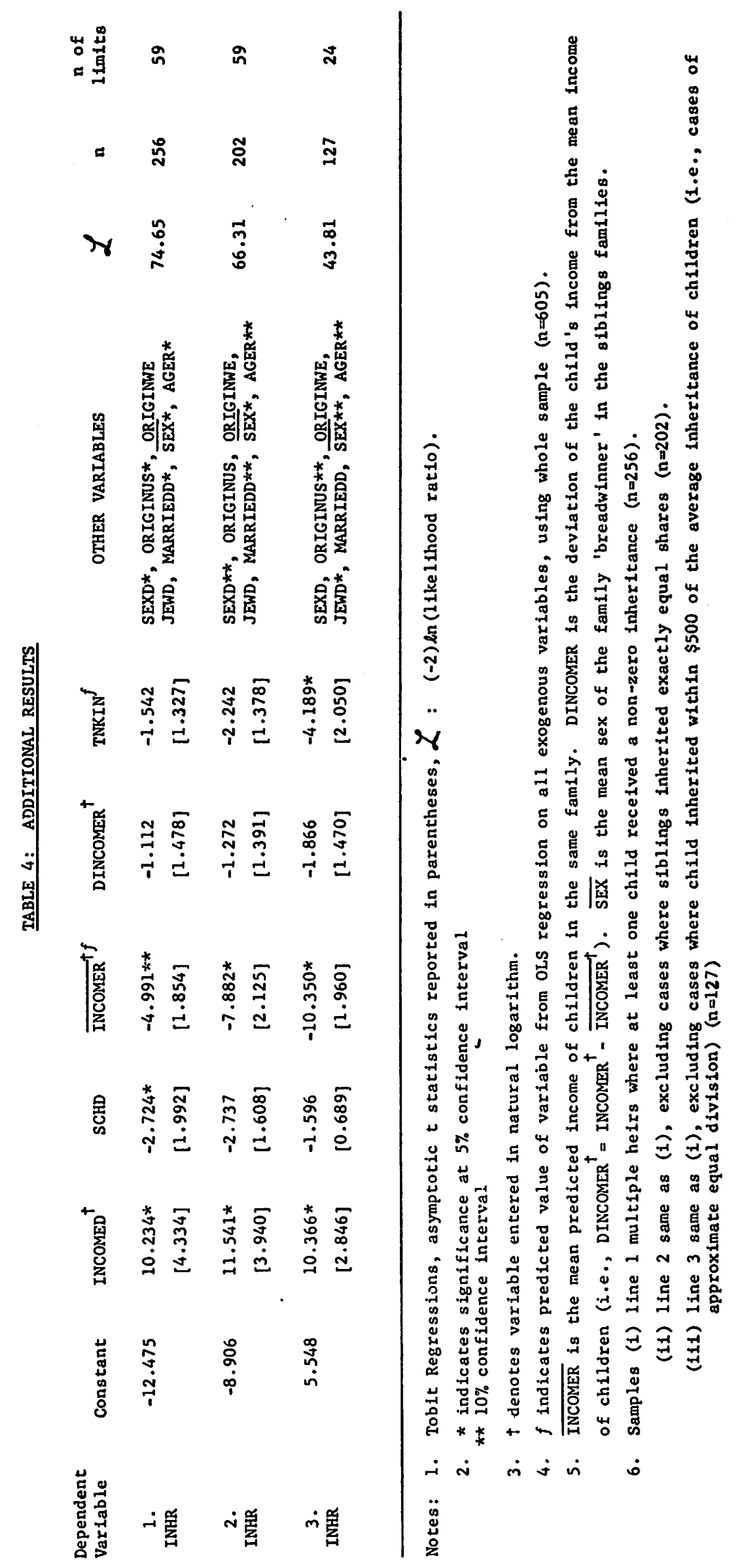




\section{SUMMARY AND CONCLUSIONS}

In this paper I have presented an altruistic model of the intergenerational transmission of inequality within the family, in which bequests of material wealth and investment in children's human capital are substitute modes of parent-child transfers. By analyzing the simultaneous determination of bequests of material wealth and human capital investment, this paper integrates two research traditions which have until recently existed in isolation.

In contrast to previous research that has emphasized inheritance as a source of inequality, the present paper emphasizes the equalizing role of inheritance in the context of the family. Holding parental income constant, children with greater endowed incomes are predicted to receive smaller transfers from their parents--thus partially offsetting the resulting inequality among members of the child generation. Transfers of material wealth are therefore predicted to be inversely related to the income of children. If greater child endowments also increase the rate of return of human capital investment, this inverse relationship will be intensified as transfers in the form of human capital are substituted for material wealth. Further, if parental schooling yields non-market returns in the form of a higher return on investment in children's schooling, more educated parents will make smaller expenditures on their progeny as they redistribute a portion of these returns toward their own consumption. More educated parents are therefore predicted to make smaller material wealth transfers, as a result of both the role of bequests in equalizing the consumption of successive generations of the family, and substitution towards a human-wealth intensive mode of intergenerational transfer.

In the context of the model developed in this paper, inequality of opportunity in the form of capital market constraints on the human capital investment of some families was shown to result in differences in the 
response of such investment to the determinants of 'ability' and 'opportunity'. In addition, as suggested by the "new microeconomics" of fertility, the choice of family size--one of the determinants of 'opportunities'--was viewed as endogenous and simultaneously determined with the level of per capita parent-child transfers.

Empirical tests of the model were performed using a unique data set containing information on the inheritance, income and schooling of the surviving kin of a random sample of estates probated in the Cleveland, Ohio area in 1964-5.

The empirical results strongly confirm the equalizing role of inheritance and the existence of substitution between human capital investment and inherited material wealth. The inheritance received by the child was found to be inversely related to the child's income. Material wealth transfers are therefore "compensatory"--in that (other things equal) children with low incomes receive greater bequests of material wealth, than their better endowed contemporaries. In addition, across families differences in parental education result in variations in inherited wealth. Greater parental education is associated with more schooling and higher incomes of children and lower bequests of material wealth--results conslstent with the theoretical predictions.

There is also evidence that the financial constraints faced by families differ across households. Families who make positive material wealth transfers appear less constrained financially, when it comes to investing in their children's human capital--and 'ability' variables are the major determinants of children's schooling. Conversely, families making zero 
bequests to children, appear more constrained financially, so that "opportunity" variables are the major determinants of child schooling. For both categories of households, there is evidence of a 'trade off' between family size (quantity) and per capita parent-child expenditures (child 'quality').

The first result is important for a number of reasons. Previous empirical work (Brittain 1978, Menchik 1980) has failed to find any evidence of compensatory bequests. In contrast, the present study provides strong evidence that within the family--between parents and children--and between families in the same income/education stratum, the distribution of inherited wealth is equalizing. This supports the recent suggestion of Griliches (1979) that the family contributes less to the intergenerational transmission of inequality than is commonly supposed, since it operates as a force for equality between successive generations (parents and children). A corollary of these findings is that the redistributive role of inherited material wealth within the family, while reducing inequality in subsequent generations, reduces the extent of social mobility as the income of each generation is more closely linked to that of preceding and succeeding generations. 


\section{APPENDIX}

In this Appendix I derive the structural and reduced form demand functions of the model under the assumption that the utility function is homothetic CES with equal elasticities of substitution between all commodities :

$(1)^{\prime} \quad U_{p}=\frac{z_{p}^{1-\alpha}}{1-\alpha}+\frac{z_{c}^{1-\alpha}}{(1-\alpha)(1+\delta)}+\frac{n^{1-\alpha}}{(1-\alpha)(1+\delta)}$

where the elasticity of substitution: $\sigma=\alpha^{-1}$ and $\delta$ is the rate of time/ generation preference--which depends on both the parent's rate of time preference and the degree of parental altruism.

The income-generating function can be written as:

(A1) $\quad I_{c}=e+k+a=e+\beta h(x, e) x+a \quad h_{x}<0, h_{e}>0$.

Relating the "output" measure of human capital transfers to the endogenous and exogenous inputs:

(A2) $\quad E k=(1-\eta) E x+\eta_{h e} E e+E B$

where $E$ represents the $\log$ derivative operator, and $\eta_{h e}=\frac{e h}{h(\cdot)}$. The assumption $h_{e}>0$ implies that greater endowed "ability" reduces the marginal cost of human capital investment. For simplicity I also assume

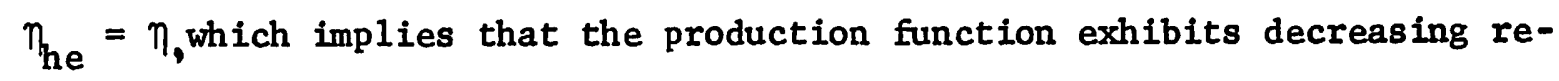
turns to scale in $x$ and constant returns' to scale with respect to increases in both $x$ and $e$.

The income concept termed "family resources" is defined following Becker and Lewis (1973) as:

$$
S=\sum_{j} \pi_{j}=I_{p}+\pi_{c} I_{c} \quad j=n, z_{p}, z_{c} .
$$

The level of human capital investment is determined by (5) which implies for constant prices:

$$
\mathrm{Ek}=\mathrm{Ex}=\mathrm{Ee}+\eta^{\prime} \mathrm{E} \beta
$$

where $\eta^{\prime}=1 / \eta$. 
The level of real family resources (A3), deflated by an index of marginal costs $\pi$, depends upon real parental income, endowments and parental efficiency:

$$
E_{r}=E S-E \Pi=\left(1-b_{c}\right) E I_{p}+b_{k} \eta^{\prime} E \beta+\left(b_{e}+b_{k}\right) E e
$$

where $S_{r}$ denotes real family resources, $I_{-}$is parental income deflated by an index of "market" prices $\left(p_{i} ' s\right): \bar{p}_{\text {, and the }} b_{j}$ 's represent shares in family resources :

$$
b_{p}=\frac{\pi_{p} z_{p}}{s} ; \quad b_{c}=\frac{\pi_{c} c_{c}}{s} ; b_{k}=\frac{p n x}{[1-\eta] S} ; b_{e}=\frac{\pi_{c} e}{s} ; b_{a}=\frac{\pi_{c}^{a}}{s} ; b_{c}+b_{n}+b_{p}=1 .
$$

The underlying (Becker-Lewis "true") demand functions express the demand for the commodities entering the utility function in terms of marginal costs $\left(\pi_{i}^{\prime} s\right)$ and family resources. In compensated form, these demand functions may be written in $\log$ derivative form as:

$(A 6)\left\{\begin{array}{l}E z_{p}=E S_{r}+b_{n} \sigma E \pi_{n}+b_{c} \sigma E \pi_{c} \\ E z_{c}=E S_{r}+b_{n} \sigma E \pi_{n}-\left(1-b_{c}\right) \sigma E \pi_{c} \\ E n=E S_{r}-\left(1-b_{n}\right) \sigma E \pi_{n}+b_{c} \sigma E \pi_{c}\end{array}\right.$

(A6) embodies the maintained hypothesis that the utility function is homothetic CES with equal elasticities of substitution $(\sigma)$ between all commodities. It is also assumed that $\pi_{p}$ is constant.

Given constant market prices $\left(\mathrm{p}_{i}^{\prime} s\right)$ marginal costs depend on commodity outputs by the relations $E \pi_{c}=E n, b_{n} E \pi_{n}=b_{a} E a+(1-\eta) b_{k} E k$. Also since $z_{c}=I_{c}=e+k+a:$

(A7) $\quad E a=\frac{I}{a} E z_{c}-\frac{k}{a} E k-\frac{e}{a} E e=\frac{b_{c}}{b_{a}} E z_{c}-\frac{b_{k}}{b_{a}} E k-\frac{b}{b_{a}} E e$.

Substituting (A7) and the determinants of marginal costs into (A6) gives the structural demand functions for family size and material wealth transfers. 
In these demand functions family size enters as a determinant of the marginal cost of child's income and the level of both material wealth and human capital transfers enter as determinants of the marginal cost of family size:

(A8)

$$
\left\{\begin{array}{l}
E a=b_{a}^{-1}\left\{b_{c} E S_{r}-b_{k}\left[1-b_{c}(1-\eta) \sigma\right] E k+b_{a} b_{c} \sigma E a-b_{c}\left(1-b_{c}\right) \sigma E n-b_{e} E e\right\} \\
E n=b_{n}^{-1}\left\{b_{n} E S_{r}-\left(1-b_{n}\right) \sigma b_{k}(1-\eta) E k-\left(1-b_{n}\right) b_{a} \sigma E a+b_{n} b_{c} \sigma E n\right\}
\end{array}\right.
$$

These two equations can be solved (respectively) for the level of material wealth transfers and family size.

Equation (A4) implies that the level of human capital investment is the outcome of an optimizing decision. In the structural demand functions which hold human capital investment constant any increase in parental efficiency must be associated with a decrease in endowments which leaves the optimum level of human capital investment unchanged, i.e., from (A4): $\mathrm{Ee}=-\eta_{\mathrm{E} \beta}$. Substituting this relationship into (A5) gives an expression for the change in real family resources, given that human capital investment is being held constant at the optimum level, i.e., $\tilde{k}=\bar{k}$ :

$$
\left.(A 5)^{\prime} \quad E_{r}\right|_{\tilde{k}=\bar{k}}=\left(1-b_{c}\right) E I_{\bar{p}}-b_{e} e^{\prime} E \beta
$$

From (A5)' it can be seen that amongst individuals with the same optimum level of human capital investment, real family resources are inversely related to parental efficiency.

Substituting (A5) ${ }^{\prime}$ into (A8) and solving for $n$ and $a$ gives the structural coefficients of parental income and efficiency when human capital investment is being held constant at the optimum level:

$$
E a=\left\{B\left[1-b_{c} \sigma\right]\right\}^{-1}\left\{\left(1-b_{c}\right) E I_{p}+B D \eta^{\prime}\left(1-b_{c}\right) E \beta-\left(1-b_{c}\right) \sigma E n-b_{c}\left[b_{e}\left(1-b_{c}\right)+b_{k} \phi\right] E \tilde{k}\right\}
$$

$$
E n=\left\{b_{n}\left[1-b_{c} \sigma\right]\right\}^{-1}\left\{b_{n}\left(1-b_{c}\right) E I_{p}-b_{n} b_{e} \eta^{\prime} E \beta-b_{a}\left(1-b_{n}\right) \sigma E a+\left[b_{e} b_{n}+b_{k} \xi\right] E \tilde{k}\right\}
$$

where $B=a / I_{c}, D=e / I_{c} \quad 0<B, D<1, \varnothing=\left\{1-b_{c}[1+(1-\eta) \sigma]\right\}>0$ if $b_{c} \leq 1 / 2$ (see below) and $\xi=\left[b_{n}-\left(1-b_{n}\right) \sigma(1-\eta)\right] \gtrless 0$. 
In these structural demand functions, which hold human capital investment constant at its optimum level, an increase in parental efficiency is predicted to increase the level of material wealth transfers and reduce family size. Conversely, if increased endowments raised the marginal cost of human capital transfers, these predicted signs would be reversed--greater parental efficiency would then be associated with lower asset transfers and a larger family size.

Consider now the alternative set of structural demand functions, which do not hold the level of human capital investment constant, but rather allow this variable to adjust in response to changes in parental efficiency and endowments. This set of demand functions can be derived by first substituting (A4) into (A7) and the expressions for the marginal costs; and then substituting the resulting expressions and (A5) into (A8) to obtain:

$(A 10)\left\{\begin{aligned} & E a=\left\{b_{a}\left[1-b_{c} \sigma\right]\right\}^{-1}\left\{b_{c}\left(1-b_{c}\right) E I\right.-b_{k} \eta^{\prime}\left[1-b_{c}(1+(1-\eta) \sigma)\right] E \beta-b_{c}\left(1-b_{c}\right) \sigma E n \\ &\left.-\left[b_{e}\left(1-b_{c}\right)+b_{k}\left\{1-b_{c}(1+(1-\eta) \sigma)\right\}\right] E e\right\} \\ & E n=\left\{b_{n}\left[1-b_{c} \sigma\right]\right\}^{-1}\left\{b_{n}\left(1-b_{c}\right) E I\right. \\ & p+b_{k} \eta^{\prime}\left[b_{n}-\left(1-b_{n}\right) \sigma(1-\eta)\right] E \beta-b_{a}\left(1-b_{n}\right) \sigma E a \\ &\left.+\left[\left(b_{e}+b_{k}\right) b_{n}-\left(1-b_{n}\right) \sigma(1-\eta) b_{k}\right] E e\right\}\end{aligned}\right.$ where $\left[1-b_{c} \sigma\right]>0$ by the second order condition that the "feedback" effects be damped (i.e., na +0 ).

Since $b_{c} / b_{a}=I_{c} / a>1$ the structural income elasticity of asset transfers is predicted to exceed that of numbers. Further, since holding $e$ and $\beta$ constant, increased parental income leaves human capital investment unchanged, while increasing the level of asset transfers, the income elasticity of asset transfers will be declining, if the underlying income elasticity of child consumption is constant. Asset transfers enter the demand function for family size with negative coefficient and vice versa. Since the coefficient of $\beta$ in the family size equation may take on either sign, the effect of parental efficiency on family size is ambiguous. 
The coefficient on parental efficiency in the equation for material wealth transfers is also in general ambiguous. However, since $0 \leq \eta, \sigma<1$ (by the second order conditions, see $A 12$ below), the term $[1+(1-\eta) \sigma]<2$. Therefore, a sufficient condition for increased parental efficiency to reduce material wealth transfers is $b_{c} \leq 1 / 2$. Since $b_{c}$ is the share of the next generation's income in family resources, this parameter measures the degree of parental altruism. In the absence of taxes $p_{a}=(1+r)^{-1}$ (where $r$ is the rate of return on assets) and defining $n=1+g$ (where $g$ is the (family) rate of population growth) for the isoelastic utility function (1)'

$$
b_{c}=b_{p}\left[\frac{1+g}{1+r}\right]^{\frac{\alpha-1}{\alpha}}(1+\delta)^{-\frac{1}{\alpha}}
$$

defining $1+\theta=b_{c} / b_{p}$ and using the approximation $\ln (1+z) \sim$, for ' $\operatorname{small'} z$ :

$$
\theta=(\mathrm{g}-\mathrm{r})+\frac{1}{\alpha}(\mathrm{r}-\delta-\mathrm{g})
$$

Therefore $\theta<0$ if $\delta>\mathrm{r}-\mathrm{g}>0$ Since this implies $b_{c}<b_{p}$ and $b_{c}+b_{p}<1$, a sufficient condition for $b_{c}<1 / 2$. is that the rate of time/generation preference $(\delta)$ exceed the rate of return net of the (endogenous) rate of population growth $(r-g)$, assuming $r-g>0$. This is a sufficient condition for material wealth transfers to be inversely related to both parental efficiency (A10) and the level of human capital investment (i.e.ф >0 in A9). Since the same term appears in the coefficient on endowments, in the demand function for assets, this condition is also sufficient for asset transfers to be negatively related to child endowments. It is also worth noting that the coefficients on the level of human capital in the equations (A9) are the same as the corresponding coefficients on child endowments in the equations (A10). The coefficients on parental income are also the same. However the coefficients on parental efficiency differ, as indicated in the text. 
In the equation for family size neither the coefficient of parental efficiency, nor that of child endowments can be signed.

Solving the equations (A10) simultaneously for $n$ and a gives the reduced form demand equations. The reduced form income elasticities are:

$(A 11)\left\{\begin{array}{l}D^{*} E a=\frac{b_{c}}{b_{a}}\left(1-b_{c}\right)(1-\sigma) E I_{-} \\ D^{*} E n=\left(1-b_{c}\right)\left[1-\frac{b_{c}}{b_{n}} \sigma\right] E I_{-}\end{array}\right.$

where the second order conditions require:

(A12) $D^{*} \equiv\left[1-2 b_{c} \sigma-\frac{b_{p}^{b} c}{b_{n}} \sigma^{2}\right]>0$.

This condition implies $\sigma<1$, since if $\sigma=1, D^{*}=-\left(b_{k} \eta+b_{e}\right)\left[1+\frac{b_{p}}{b_{n}}\right]<0$.

Since $\sigma<1$, this implies the reduced form income elasticity of material wealth transfers is positive. However, since $b_{c}>b_{n}$, the reduced form income elasticity of family size may take on either sign and will be negative if $\mathrm{b}_{\mathrm{I}} \sigma>\mathrm{b}_{\mathrm{n}}$.

The difference between the reduced form and structural income elasticities for material wealth transfers (A11 and $A 9$ or $A 10$ ) is given by the expression:

$$
\left[\eta_{a I_{-}}^{R F}-\eta_{a I_{p}}^{S T}\right]=\frac{\left(I-b_{c}\right)^{2} \sigma}{B D{ }^{*}\left[1-b_{c} \sigma\right] b_{n}}\left\{b_{c} \sigma-b_{n}\right\} \sum 0 \text { as } b_{c} \sigma \sum b_{n}
$$

where the superscript RF designates the reduced-form elasticity and ST the structural income elasticity. Thus if $b_{c} \sigma>b_{n}$, the reduced form income elasticity of family size is predicted to be negative and the reduced form income elasticity of material wealth transfers is predicted to exceed the corresponding structural coefficient. 
The coefficients for the reduced form elasticities of asset transfers and family size with respect to parental efficiency are ommitted, since they are more complex. It can be shown that the effect of parental efficiency on family size is ambiguous, while greater parental efficiency will be associated with reduced material wealth transfers, if the returns to scale in human capital investment (with respect to $x$ ) do not exceed one-half (Tomes, 1978a pp. 180-182). 
Table A1

MEANS OF VARIABLES FOR VARIOUS SAMPLES

I All sons/daughters reporting positive

VARIABLE

INHR (\$000's)

INCOMER ( $\left.\$ 000^{\prime} s\right)$

SCHR

AGER

SEXR (\% female)

NEMPLR

NLABINC

(\% reporting the receipts of non labour income?

SINGLER (\%)

DIV/SEPR (\%)

INCOMED ( $\$ 000$ 's)

SCHD

AGED

SEXD (\% female)

MARRIEDD (\%)

TNKIN

OTHERKIN

RACE (\% non white)

CATHD (\%)

PROTD (\%)

JEWD (\%)

ORIGINUS (\%)

ORIGINWE (\%)

42.828

49.3

1.190

29.8

9.6

0.3

6.085

9.102

70.630

41.7

58.8

4.134

1.020

3.3

44.1

43.6

5.1

51.6

16.2
II Sons/daughters in I receiving an inheritance in excess of the limit value $\mathbf{n}=354$
III Sons/daughters

in I receiving an inheritance equal to the limit value $\mathrm{n}=251$

0.0

10.973

12.645

40.633

48.6

50.2

1.184

1.199

31.4

27.5

9.0

10.4

0.3

0.4

5.559

6.906

9.054

9.171

72.056

68.618

52.5

26.3

39.5

86.1

3.791

0.743

4.618

1.410

2.7

5.6

44.9

43.0

41.5

46.6

6.2

3.6

45.2

60.6

18.1

13.5 


\section{Footnotes}

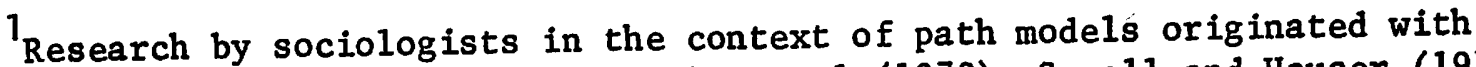
Blau and Duncan (1967) and includes Jencks et al (1972), Sewall and Hauser (1975). See also Corcoran et al (1976). Some early contributions by economists are contained in Schultz (ed) (1972).

2 In the context of the model of Becker-Tomes (1979), it can be shown that if the marginal propensity of parents to transfer resources to children exceeds the inheritability of endowments, the relative inequality in income in equilibrium (as measured by the coefficient of variation) is less when parents choose the optimum level of transfers, than if there were no intergenerational transfers.

${ }^{3} \mathrm{~A}$ further limitation of these studies is that estimates of the income (wealth) elasticity of bequests do not distinguish between alternative models of bequest behavior. Both altruistic models and models of "egoistic" lifecycle accumulation in the presence of uncertain lifetimes and imperfect capital (annuity) markets are consistent with a high income elasticity of bequests (see Tomes 1979).

4 Blinder suggests that "the taste for bequests... would rise with the number of children" (1976, p. 90).

$5_{\text {This assumption rules out unplanned bequests when lifecycle savings }}$ for future consumption become bequests due to the uncertain incidence of mortality。 Bevan and Stiglitz (1978) and Tomes (1979) discuss such models. In. the present model all bequests are planned and are motivated by parental altruism.

${ }^{6} \mathrm{~A} 11$ households are assumed to be composed of two parents plus children. I do not distinguish between the consumption of individual parents.

${ }^{7}$ Becker and Tomes (1976) considef differences in transfers to children within the same family, when children differ in endowed ability。

8 We assume that all parents are at the interior solution where net parent-child transfers are positive--i.e., altruistically motivated transfers are non-zero. Even with the secular growth of incomes over the generations, the presence of sufficient regression towards the mean in endowed income and reverse (child-parent) transfers effected by bond-financed fiscal policies and social security programs would tend to make positive private parent-child transfers optimal for at least some households. Given the observed prevalence of "forward" transfers in forms such as schooling this assumption to us seems plausible. 
9 Becker and Tomes (1979) consider intergenerational transfers in the context of many generations.

10 For simplicity stocks of both human capital and material wealth are measured in units of the child's income. Note also that in general e would represent a vector of earning and learning "abilities".

${ }^{11}$ We assume, following Gronau (1977), that home produced inputs into the production of children's human capital are perfect substitutes for market purchased inputs of equal quality. The aggregate input $x$ is the sum of these components: $x=x_{m}+x_{h}=x_{m}+f(h)$ where $x_{m}$ represents market purchased inputs (kindergartens, private schools, colleges, etc.) and $x_{h}$ represents home produced inputs which utilize the home-time of parents: $h$. Al1 households are assumed to purchase market produced inputs and the marginal product of parent's home-time is assumed to be diminishing (i.e., $f^{\prime}>0, f^{\prime \prime}<0$ ). The marginal price of inputs is therefore the price of the market-purchased input. Also, following Michael (1973), we assume that parental efficiency is "neutral" in that greater efficiency increases the marginal product of home-produced and market purchased inputs in proportion. An alternative specification would be that greater parental efficiency increases only the marginal product of home inputs, 1.e.: $x=x_{m}+\beta f(h)$. We assume (in contrast to Michael) that parental efficlency (human capital) is "biased" between commodities, in that greater parental efficiency raises the marginal product of inputs into the production of children's human capital relative to productivity in both parent's own consumption and fertility.

${ }^{12}$ Since all children have equal endowments and the same income-generating function (2), human capital investment and material wealth transfers will be equal for all children within a given family.

${ }^{13}$ In the absence of estate and income taxes $P_{a}=[1+r]^{-1}$ where $r$ equals the intergenerational rate of return on assets. This parameter could be sizeable, for example if generations were separated by 20 years and the annual rate of return on assets is $3 \% \mathrm{r}=0.82$.

${ }^{14}$ In this figure and those following, I assume for simplicity that family size ( $n$ ) is given exogenously as $n=1$.

${ }^{15}$ This conclusion differs from that reached by Edwards and Grossman (1977) who appear to neglect the income effect and thus conclude that inequality will be greater in the presence of "equal opportunity" (i.e., no financial liability constraint). However, since the absence of the financial liability constraint allows the family to reap the producer surplus rents on additional units of human capital investment, the income of the two-generation family is greater under these circumstances--leading to an offsetting income effect. 
${ }^{16}$ See equations (A9) and (A10) in the appendix, and the related discussion. The net effect of endowments on child numbers is ambiguous. Increased endowments lead to greater human capital investment, which raises the marginal cost of numbers--resulting in a negative substitution. Increased endowments also raise the resources of the two generation family which produces a positive income effect, assuming family size is a normal good. Hence the net effect of child endowments (and therefore human capital investment) on family size is ambiguous.

17 This figure is based on that presented by Edwards and Grossman (1977) in the context of a "two-regime" model dealing with children's health and ability.

${ }^{18}$ Heckman's estimates of the returns to scale in the production of human capital for various education groups do not differ significantly from 1/2 [Heckman 1976, Table 3A, p. S36].

${ }^{19}$ The mean gross estate of decedents was $\$ 12,000$ and less than $5 \%$ of decedent's estates in this sample exceeded $\$ 60,000$ after deductions and were liable for Federal Estate Tax (Sussman et. al p. 188). Ohio had (in 1964-5) an inheritance tax which commenced at $1 \%$ on the inheritance of children in excess of $\$ 7,000-$-almost double the mean inheritance in the data $I$ use.

Information gleaned from the Barlow-Brazer-Morgan (1966) Economic behaviour of the affluent survey suggests that the omission of data on gifts may not be a serious problem in terms of omitted variable bias (see the earlier version of this paper), and also suggests that the income elasticity of gifts exceeds that of bequests. Menchik's study of large Connecticut estates supports this latter conclusion (Menchik 1979, Table 4).

20 The years of schooling measure omits preschool investment (where the quantity and quality of parental time inputs have been found to be important [Liebowitz 1974]), the quality of schooling and post-school investments.

${ }^{21}$ An attempt is made to hold constant non-labour income, by introducing a dummy variable for the presence/absénce of non-labour income. In addition the number of individual's in the household employed is included to hold constant differences in labour supply between households.

22 The static model presented in the text is not identified, in the absence of restrictions implied by lifecycle factors. However, if "fixed cost" components of material wealth transfers and family size are introduced then there exists a special case in which the model is identified (see Tomes 1978b). A necessary condition for identification in the present context is that the catholic/non catholic status of the decedent have a larger effect on the fixed cost of family size than on the fixed cost of material wealth transfers and conversely Jewish/non Jewish status have a larger effect on the fixed cost of material wealth transfers. The first condition seems plausible if catholics face a higher psychic cost of contraception. The second condition is possible if Jews, with a greater expectation of the expropriation of material wealth based upon their past cultural history, attach a premium to wealth in the form of human capital (see Brenner and Kiefer 1978). 
${ }^{23}$ Sussman et. al. in their original study concluded on the basis of a tabular analysis that "the percentage of survivors who inherited did not vary greatly among [survivor] income categories." But also reported that "those most likely to inherit were persons with the smallest monthly incomes" (p. 155). A subsequent analysis of these data by Brittain (1978), designed to detect differences in inheritance by the sex of recipient also reported that "'need' for bequests indicated by the prebequest economic status of the son and daughter was tested, but found to have no influence. This is...consistent with equal division among siblings." (1978 p. $45 \mathrm{fn} .47$ ) However Brittain's regression (pp. 42-45) included only the number of children and the gross estate of the decedent as regressors in addition to the recipient's sex. Adams (1980) also analyzed these same data, to estimate the income elasticity of bequests but since the income of children was used as a measure of the decedent's income, he did not separate the effects of child's income and parent's income on material wealth transfers.

24

This coefficient is 'large' in comparison to estimates of the 'rate of return' to schooling. However the dependent variable is the log of family income rather than individual earnings. If both the education levels and earnings of spouses are positively correlated this could explain the 'large' marginal effect of schooling.

${ }^{25}$ In the regression reported in line 5 the inheritance variable was predicted using a Tobit regression to take account of the truncation problem. The results when this variable is entered in the usual manner are not substantially different from the results reported here.

${ }^{26}$ The probit regression included all the exogenous variables. The presence of the selection rule introduces heteroscedasticity into the equation residuals resulting in upward biased t-statistics. However in the present context there is a presumption that the bias is small. First, the computed lambda variable is rarely significant (lines 4,5 and 8 ). Second, applying the appropriate correction procedure to the t-statistics from the 2SLS estimates resulted in only marginal changes in the, $t$-statistics.

27 In the present sample the incidence of equal division is much lower than found by Menchik (1980) in his sample of large Connecticut estates.

${ }^{28}$ For this subsample $(n=191)$ the effects of mother's and father's education, ages and incomes were analyzed, also a measure of the predicted bequest from the surviving spouse to children was constructed and used in subsequent regressions. The results, which confirm the basic conclusions of this study, were reported in the earlier version of this paper. 


\section{$\underline{\text { References }}$}

Adams, James D., "Personal Wealth Transfers," forthcoming in Quarterly Journal of Economics, 1980.

Barlow, Robin, Brazer, Harvey, E. and Morgan, James, N., Economic Behavior of the Affluent, The Brookings Institution, Washington, D.C. 1966.

Barro, Robert J., "Are Government Bonds Net Wealth?" Journal of Political Economy Vo1. 82 No. 6 (December 1974), pp. 1095-1117.

Becker, Gary, S., Human Capital and the Personal Distribution of Income: An Analytical Approach, Institute of Public Administration, University of Michigan, Ann Arbor 1967.

"A Theory of Social Interactions," Journal of Political Economy, Vol. 82, No. 6 (Nov。/Dec。1974), Pp。1063-94.

, and Lewis, H. Gregg, "On the Interaction Between the Quantity and Quality of Children," Journal of Political Economy, Vo1. 81, No. 2, part 2 (March/April 1973), Pp. S279-88。

, and Tomes Nigel, "Child Endowments and the Quantity and Quality of Children," Journal of Political Economy, Vo. 84, No. 4, part 2 (August 1976), PP. S143-62.

, and "An Equilibrium Theory of the Distribution of Income and Intergenerational Mobility," Journal of Political Economy Vo1. 87 No. 6 (December 1979), pp. 1153-1189.

Bevan, D. and Stiglitz, J. E., "The Wealth Distribution and Inheritance," paper presented at AEA Meetings, Chicago, August 1978.

Blinder, Alan, S., "A Model of Inherited Wealth," Quarterly Journal of Economics, Vol. 87, No. 4 (November 1973), Pp. 608-26.

, "Intergenerational Transfers and Life Cycle Consumption," American Economic Review, Papers and Proceedings, Vol. 66 (July 1976), PP. 87-93.

, "Inequality and Mobility in the Distribution of Wealth," Kyklos, Vol. $29(1976 \mathrm{~b})$, pp。607-38。

Blau, Peter, M., and Duncan, Otis, Dudley, The American Occupational Structure, New York: Wiley, 1967.

Blomqvist, N. S., "The Inheritance Function," Journal of Public Economics Vo1. 12 (1979), pp. .41-60.

Brenner, Reuven, and Kiefer, Nicholas, "The Economics of Diaspora," Center for Mathematical Studies in Business and Economics, University of Chicago, Research Report, No. 7843, 1978 .

Brittain, John, A。, Inheritance and the Inequality of Material Wealth, The Brookings Institution, Washington, D。C. 1978 . 
Corcoran, Mary, Jencks, C., and Olneck, M., "The Effects of Family Background on Earnings," American Economic Review Vo1. 66 (May 1976), pp. 430-435.

Edwards, Linda, N. and Grossman, Michae1, "An Economic Analysis of Children's Health and Intellectual Development," Working Paper, No. 180, N.B.E.R., New York, May 1977.

Griliches, Zvi, "Sibling Models and Data in Economics: Beginnings of a Survey," Journal of Political Economy Vo1. 87, No. 5, Part 2 (October 1979), pp. s37S64.

Gronau, Reuben, "Leisure, Home Production and Work: The Theory of the Allocation of Time Revisited," Journal of Political Economy, Vo1. 85, No. 6, (December 1977), pp. 1099-1124.

Harbury, Colin, D., "Inheritance and the Distribution of Personal Wealth in Britain," Economic Journal, Vo1。 72 (1962), pp.845-63.

, and McMahon, P., "Inheritance and the Characteristics of Top Wealth Leavers in Britain," Economic Journal, Vo1. 83 (September 1973), Pp. 810-833.

, and Hitchens, $D_{\circ}$, "The Inheritances of Top Wealth Leavers: Some Further Evidence," Economic Journal, Vol。 86 (June 1976), pp.321-326.

Heckman, James, J., "A Life Cycle Model of Earnings, Learning and Consumption," Journal of Political Economy, Vol。84, No. 4, part 2 (August 1976), PP. SW-S44.

, "The Common Structure of Statistical Models of Truncation, Sample Selection and Limited Dependent Variables, and a Simple Estimator for Such Models," The Annals of Economic and Social Measurement Vol. 5 (1976b), Pp. 475-492.

, "Sample Selection Bias as a Specification Error," Report, No. 7720, Centre for Mathematical Studies in Business and Economics, University of Chicago, Econometrica Vo1. 47 No. 1 (January 1979), Pp. 153-162.

Ishikawa, Tsuneo, "Family Structures and Family Values in the Theory of Income Distribution," Journal of Political Economy, Vol. 83, No. 5 (October 1975), pp. 987-1008.

Jencks, Christopher, et al。, Inequality: A Reassessment of the Effect of Family and Schooling in America, New York: Basic 1972.

Knight, Frank H., Risk, Uncertainty and Profit (1921), reprinted New York, Kelley and Millman Inc., 1957.

Lebergott, Stanley, "Are the Rich Getting Richer? Trends in $\nabla_{0}$. Wealth Concentration," Journal of Economic History, Vol. 36, No. 1 (March 1976), pp. 147-162。

Leibowitz, Arleen, "Home Investments in Children," Journal of Political Economy, Vol. 82, No. 2, part 2 (March/April 1974), pp。s111-s131. and Friedman, Bernard, "Family Bequests and the Derived Demand for Health Inputs," Economic Inquiry Vol. 17, No. 3 (July 1979), pp. 419-434. 
Menchik, Paul, L., "Primogeniture, Equal Sharing and the U.S. Distribution of Wealth," Discussion Paper 390-77, Institute for Research on Poverty, University of Wisconsin, forthcoming in Quarterly Journal of Economics (1980).

, "Inter-generational Transmission of Inequality: An Empirical Study of Wealth Mobility," Economica, Vol. 46 (November 1979).

Michael, Robert T., The Effect of Education on Efficiency in Consumption, New York: National Bureau of Economic Research, 1973.

Parsons, Donald, $0_{0}$, "Intergenerational Wealth Transfers and the Educational Decisions of Male Youth," Quarterly Journal of Economics, Vol. 89, No. 4 (November 1975), pp。603-617。

Pryor, F. L., "Simulation of the Impact of Social and Economic Institutions on the Size Distribution of Income and Wealth," American Economic Review, Vol。73, No.1 (March 1973), pp。50-73。

Rosen, Sherwin, "Income Generating Functions and Capital Accumulation," Harvard Institute of Economic Research, June 1973.

Sewal1, William, $H_{\bullet}$, and Hauser $R_{0} M_{\bullet}$, Education, Occupation and Earnings: Achievement in Early Career, Academic Press, New York 1975.

Schultz, T. W. (ed.), "Investment in Education: The Equity-Efficiency Quandary," Journal of Political Economy, Vol。80, No。3, part 2 (May/June 1972).

Stamp, Josiah, "Inheritance as an Economic Factor," Economic Journal, Vol。 36 (1926), Pp. 347-48.

Stiglitz, J. E., "Notes on Estate Taxes, Redistribution and the Concept of Balanced Growth Path Incidence," Journal of Political Economy, Vo1. 86 No. 2, Part 2 (Apri1 1978), pp. S137-S150.

Sussman, Marvin, $B_{0}$, Cates, Judith $\mathrm{N}_{0}$, and Smith, David $\mathrm{T}_{0}$, The Family and Inheritance, Russell Sage Foundation, New York 1970。

Tomes, Nigel, "A Model of Child Endowments and the Quality and Quantity of Children," unpublished $\mathrm{Ph}, \mathrm{D}$ dissertation, University of Chicago 1978a。 , "A Model of Fertility and Children's Schooling, Department of Economics, U.W.O., Research Report, 7826, 1978b。 , "Uncertain Lifetimes, Imperfect Capital Markets and the Altruistic Motive for Bequests," Department of Economics U.W.O., Research Report 7930 (October 1979).

Wedgwood, J., "The Influence of Inheritance on the Distribution of Wealth," Economic Journal, Vo1. 38 (1928), Pp. 38-55. 